1

21

22

5

\section{Comparative Performance of M-MCM-41 (M: Cu, Co, Ni, Pd, Zn and Sn) Catalysts for Steam Reforming of Methanol}

(1)

(1)

(1)

8

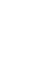

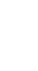

1

2

3

4

6

7

8

\author{
Richard Y. Abrokwah ${ }^{\mathrm{a}}$, Vishwanath G. Deshmane $\mathrm{e}^{\mathrm{b}, \mathrm{c}^{*}}$, Debasish Kuila $^{\mathrm{c}^{*}}$
}

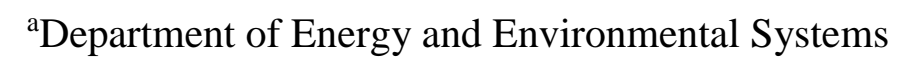

${ }^{\mathrm{b}}$ Department of Chemical, Biological and Bioengineering

cDepartment of Chemistry

North Carolina Agricultural and Technical State University

Greensboro, NC 27411 USA 
2 One-pot hydrothermal procedure was used to synthesize high surface area M-MCM-41 (M: Cu,

$3 \mathrm{Co}, \mathrm{Ni}, \mathrm{Pd}, \mathrm{Zn}$, and $\mathrm{Sn})$ nanocatalysts. The M-MCM-41 catalysts containing $10 \mathrm{wt} \%$ of different

4 metals were examined to evaluate the performance of individual metals in steam reforming of

5 methanol (SRM) in terms of activity, selectivity and long term stability under similar operating

6 conditions. The fresh and spent catalysts were characterized using BET, XRD, TGA-DSC, TEM,

7 TPR, ICP-OES, EDX, Raman, and FTIR analytical techniques. Cu-MCM-41 showed the best

8 performance in terms of activity and selectivity among the different catalysts investigated in this

9 study. The overall SRM reactivity trend for different metals based on methanol conversion

10 followed the order: Cu-MCM-41 > Pd-MCM-41 > Sn-MCM-41 > Ni-MCM-41 $\approx$ Zn-MCM-41 >

11 Co-MCM-41. The catalytic performance of $\mathrm{Cu}-\mathrm{MCM}-41$ at $250{ }^{\circ} \mathrm{C}$ using 1:3 methanol-water mole

12 ratios showed $100 \% \mathrm{H}_{2}$ selectivity, $\sim 6 \% \mathrm{CO}$, and no methane formation. The time-on-stream

13 studies conducted continuously for $40 \mathrm{~h}$ at $300{ }^{\circ} \mathrm{C}$ revealed that $\mathrm{Cu}-\mathrm{MCM}-41$ was the most stable

14 catalysts and displayed consistent steady state conversion (up to74\%). The SRM activity of Pd, Sn

15 and Zn was comparatively better; however, they deactivated steadily with time. Although coking

16 was a major factor in deactivation of the catalysts, degradation of the mesoporous structure and

17 thermal sintering appeared to play an influential role in deactivation, particularly in the case of Sn-

18 MCM-41.

19 Keywords: One-pot synthesis; metal-MCM-41 catalysts; steam reforming of methanol; catalyst 20 stability; $\mathrm{Cu}, \mathrm{Co}, \mathrm{Ni}, \mathrm{Pd}, \mathrm{Zn}$, and $\mathrm{Sn}$. 


\section{Introduction}

Transition from non-replenishable fossil fuel energy to alternative clean energy such as hydrogen is no longer an academic debate. Catalytic steam reforming of renewable alcohols (e.g. methanol, glycerol and ethanol) is a highly favored route to produce hydrogen to generate electricity, as well as, to power portable electronic gadgets and vehicles using fuel cell technology. Traditionally, copper based catalysts supported on $\mathrm{Al}_{2} \mathrm{O}_{3}, \mathrm{ZnO}$ and $\mathrm{ZrO}_{2}$ have been studied and used for commercial alcohol steam reforming processes [1-3]. Recently, Zhang et al. [4] showed that $\mathrm{Cu}$ supported on three different supports $\left(\mathrm{CeO}_{2}, \mathrm{ZrO}_{2}\right.$ and $\left.\mathrm{CeO}_{2}-\mathrm{ZrO}_{2}\right)$ exhibited significant contrast in catalytic performance towards steam reforming of methanol. Hirunsit and Faungnawakij demonstrated that $\mathrm{Cu}$-based spinel-lattice catalysts possess high thermal stability which suppresses $\mathrm{Cu}$ sintering at high reaction temperature [5]. In contrast, we and others [6-10] have focused on the use of high surface area mesoporous supports (e.g. MCM-41, SBA-15, and $\mathrm{TiO}_{2}$ ) for steam reforming, which tend to avail a high catalytic surface area with well defined large pore sizes mitigating the catalyst deactivation (via sintering) by enhancing uniform dispersion of the active metal particles. Recently, the versatility and robustness of these mesoporous silica nanomaterials (MSNs) as inorganic supports have been extensively and critically reviewed byYamamoto et al [11] and other research groups $[12,13]$. The researchers pointed out several advantages of these materials including biocompatibility, high rigidity, high surface areas, tunable mesopores and easy functionalization of their pore interiors and surfaces with drugs, organic molecules and metal oxides.

Several catalytic systems have been used over the years for steam reforming reactions. Riva et al. [14] elucidated that cobalt (Co) catalysts supported by $\mathrm{TiO}_{2}$ and $\mathrm{SiO}_{2}$ exhibit remarkable differences in their binding energy. They inferred that $\mathrm{Co}-\mathrm{TiO}_{2}$ interactions were strong and made 
1 Co very resistant to reduction while the weaker $\mathrm{Co}_{-} \mathrm{SiO}_{2}$ interactions resulted in sintering and low

2 reactivity. The high reactivity of nickel (Ni) supported on $\mathrm{MCM}-41, \mathrm{La}_{2} \mathrm{O}_{3}, \mathrm{Al}_{2} \mathrm{O}_{3}$, yttria-

3 stabilised zirconia (YSZ), and $\mathrm{MgO}$ catalysts in steam reforming reactions to produce hydrogen

4 have also been studied extensively [15-17]. Incorporation of tin ( $\mathrm{Sn})$ and zinc ( $\mathrm{Zn})$ are reported to

5 promote the water-gas shift and/or methanation reactions [3, 18, 19]. Palladium (Pd) is generally

6 used as a promoter to bolster the conversion of steam reforming reactions due to its inherent ability

7 to (i) improve reducibility of other metals and (ii) form substitutional and intermetallic alloys,

8 particularly with $\mathrm{Zn}$ and $\mathrm{Ni}[20]$.

9 While the aforementioned studies are certainly useful and informative, the catalysts

10 (different combinations of the metals and supports) were synthesized using different approaches,

11 and utilized for different feedstocks under different steam reforming experimental conditions.

12 Therefore, a comparative in-depth study of the intrinsic physicochemical properties and catalytic

13 performance of supported metals prepared by one particular method, and tested under similar

14 experimental conditions could provide a platform to get invaluable insights into the reasons for

15 any stark contrasts in their catalytic behaviors. In addition, such a thorough investigation of each

16 metal-support system could predict how they could be stoichiometrically combined in tailoring

17 efficient and robust multi-metallic catalytic systems. In this study, we report synthesis of

18 mesoporous catalysts using a one-pot hydrothermal method, and insights into how the interactions

19 between each individual metal and MCM-41 support impact their SRM performance under

20 identical experimental conditions in a packed bed reactor. The contrast in behavior of each metal

21 towards methanol conversion, selectivity for hydrogen, methane, carbon monoxide and carbon

22 dioxide during steam reforming of methanol, and the stability of the catalysts are discussed. 


\section{Experimental}

\section{2.1. Materials and Methods}

All the reagents utilized were analytical grade and used without further purification.

4 Tetramethylorthosilicate, 99\% (TMOS) and ammonium hydroxide, ACS (American Chemical 5 Society) reagents, were purchased from Acros Organics, New Jersey, USA. 6 Cetyltrimethylammoniumbromide (CTAB), Ni(NO$)_{2} .6 \mathrm{H}_{2} \mathrm{O}, \mathrm{Cu}\left(\mathrm{NO}_{3}\right)_{2} .2 .5 \mathrm{H}_{2} \mathrm{O}, \mathrm{CoCl}_{2} .6 \mathrm{H}_{2} \mathrm{O}$, $7 \mathrm{Pd}\left(\mathrm{NO}_{3}\right)_{2}, \mathrm{Zn}\left(\mathrm{NO}_{3}\right)_{2} \cdot 6 \mathrm{H}_{2} \mathrm{O}$ and $\mathrm{SnCl}_{2} \cdot 2 \mathrm{H}_{2} \mathrm{O}$ were procured from Sigma-Aldrich, Missouri, USA.

8 Ethanol anhydrous and acetone, ACS reagents were purchased from Fischer Scientific, New 9 Jersey, USA. The de-ionized water used for all experiments was purified using a Mill-Q Advantage A10 Elix 5 system obtained from Millipore Corporation (Bedford, MA, USA).

\subsection{Catalyst Synthesis}

MCM-41 supported mono-metallic (M-MCM-41; M: Cu, Co, Ni, Pd, Sn, and Zn) catalysts were synthesized using a one-pot hydrothermal procedure [21]. The molar composition ratios of the reagents used were: 1TMOS: 0.13CTAB: $130.6 \mathrm{H}_{2} \mathrm{O}: 20$ Ethanol. The quantity of metal precursors used was based on the expected $10 \mathrm{wt} \%$ metal loading in the final mesoporous matrix. Since all the synthesized catalysts have $10 \mathrm{wt} \%$ metal loading, it is not included in the designation

17 of the catalysts in rest of the writeup. In a typical synthesis, the surfactant (CTAB) was weighed, 18 dissolved in de-ionized water at $30{ }^{\circ} \mathrm{C}$ and stirred to get a colorless solution A. Another solution designated B was prepared by dissolving the metal precursors in ethanol. Solution B was gently poured into solution A and stirred for 30 min. To this mixture, the limiting reagent (TMOS) was added drop-wise and stirred continuously for another $30 \mathrm{~min}$. Ammonium hydroxide was then

22 added drop-wise to precipitate the metal hydroxides at $\mathrm{pH}$ 10. The solution was then stirred for 23 another $3 \mathrm{~h}$ and then aged in an oven at $65^{\circ} \mathrm{C}$ for $18 \mathrm{~h}$. The obtained precipitate was washed with 
1 de-ionized water and ethanol to get a filtrate of $\mathrm{pH} 7$. The filtered material was air dried for $\sim 24 \mathrm{~h}$,

2 followed by oven drying at $110{ }^{\circ} \mathrm{C}$ for $24 \mathrm{~h}$. The catalyst was calcined at $550{ }^{\circ} \mathrm{C}$ for $16 \mathrm{~h}$ at a

3 heating and cooling rate of $2{ }^{\circ} \mathrm{C} / \mathrm{min}$ to remove the surfactant (CTAB).

$4 \quad$ 2.3. Catalyst Characterization

Specific surface area, pore-size, and pore volume of the catalysts were determined using a

6 Quantachrome NOVA 2200e instrument (Quantachrome Instruments, Boynton Beach, FL, USA).

7 The surface area was calculated using the Brunauer-Emmett-Teller (BET) equation from the

8 adsorption branch of the isotherm in a relative pressure $\left(\mathrm{P} / \mathrm{P}_{0}\right)$ range of $0.07-0.3$. The average BET

9 surface area of $1.0 \pm .002 \mathrm{~m}^{2}$ was determined with a confidence level of $95 \%$. The total pore volume

10 was evaluated depending on the amount of $\mathrm{N}_{2}$ adsorbed at a $\mathrm{P} / \mathrm{P}_{0}=1$. The pore size distribution and

11 average pore sizes were determined by means of a non-local density functional theory (NLDFT)

12 method [22].

13 The $\mathrm{H}_{2}$ temperature programmed reduction (TPR) analysis was carried out with the

14 AutoChem II 2920 Chemical Analyzer from Micromeritics Instrument Corp. (Norcross, GA,

15 USA) equipped with a TCD detector. In a typical analysis, gas stream $\left(10 \% \mathrm{H}_{2} / \mathrm{Ar}\right)$ at a flow rate

16 of $50 \mathrm{ml} / \mathrm{min}$ was flown through $\sim 30 \mathrm{mg}$ of catalyst while the temperature was increased from

17 room temperature to $1000^{\circ} \mathrm{C}$ at a $10^{\circ} \mathrm{C} / \mathrm{min}$ ramp rate.

18 The small and wide angle powder X-ray diffractions(XRD) were recorded using a D8

19 discover X-ray diffractometer from Bruker (Bruker Optics, Inc., Billerica, MA) with PSD detector,

20 using $\mathrm{Cu} \mathrm{K \alpha}$ radiation generated at $40 \mathrm{~mA}$ and $40 \mathrm{kV}$ at the scanning rate of $0.014 \%$ s. The crystal

21 sizes of the metal oxides were determined using Scherrer equation.

$22 \tau=\frac{0.9 \lambda}{\beta \cdot \cos \theta}$ 
1 Where, $\tau$ is the crystal size, $\lambda$ is the wavelength of the $\mathrm{Cu} \mathrm{K \alpha}$ radiation, $\beta$ is the full width half

2 maximum and $\theta$ is the Braggs diffraction angle. Thermogravimetric (TGA) and differential

3 scanning calorimetry analyses (DSC) were performed using the SDT Q600 V20.4 Build 14 system

4 (TA Instruments, New Castle, DE, USA) at a heating rate of $10{ }^{\circ} \mathrm{C} / \mathrm{min}$ with air flow rate of 100

$5 \mathrm{ml} / \mathrm{min}$. The empirical elemental compositions were estimated using inductively coupled plasma

6 optical emission spectroscopy (ICP-OES) Agilent 710-ES spectrometer and energy dispersive X-

7 ray spectroscopy (EDX)-Zeiss EVO LS10 scanning electron microscopy (SEM) equipped with

8 Oxford INCA X-act detector. The ICP-OES samples were prepared by dissolving $75 \mathrm{mg}$ of the

9 catalyst in a mixture of $2 \mathrm{ml}$ hydrofluoric acid (51\%) and $3 \mathrm{ml}$ nitric acid (68\%), and heated gently

10 to $80{ }^{\circ} \mathrm{C}$ until complete dissolution of the catalysts. Prior to elemental analysis, the metal solution

11 was diluted with $1000 \mathrm{ml}$ de-ionized water and filtered.

The Fourier transform infrared (FTIR) spectra were recorded using Shimadzu IR Prestige-

1321 Fourier transform infrared 8300 spectrometer equipped with liquid- $\mathrm{N}_{2}$-cooled mercury14 cadmium-telluride (MCT) detector. To maintain a suitable balance between the signal resolution 15 and ripple size effects, the Happ-Genzel apodization function was used. The $\mathrm{KBr}$ pelletization 16 method was employed for the sample preparation and the spectrum was recorded at room 17 temperature in the range of 400 to $4000 \mathrm{~cm}^{-1}$ at $4 \mathrm{~cm}^{-1}$ resolution. (CCD) detector and integrated with an internal laser of $785 \mathrm{~nm}$. The catalysts were placed on a

21 very clean microscopic slide for spectral acquisition, focused with a laser at 50x working distance

22 objective and the spectra were recorded using 600 groves $(\mathrm{mm})$ grating. The background was then 23 subtracted from the acquired spectra. 
$\mathrm{GmbH}$, Oberkochen, Germany) transmission electron microscope (TEM) operated at an accelerating voltage of $120 \mathrm{kV}$. First, a small quantity of the catalyst was dispersed in $3 \mathrm{ml}$ of

4 ethanol and sonicated for few minutes. Then, a Lacey carbon coated grid, 300 mesh size, with $63 \mu \mathrm{m}$ grid size was slowly dipped several times in the mixture. The grid was then placed in a

6 sample holder and dried in an oven at $100{ }^{\circ} \mathrm{C}$ for $12 \mathrm{~h}$.

\subsection{Catalyst Activity Test}

The SRM tests were performed at atmospheric pressure in a continuous up flow stainless steel fixed bed reactor (Tube ID: $6.22 \mathrm{~mm}$ ). A methanol/water molar ratio of 1/3 and a GHSV of $2838 \mathrm{~h}^{-1}$ at STP was maintained for all the reactions. Catalysts were activated $e x$-situ in a tubular furnace using $10 \% \mathrm{H}_{2} / \mathrm{Ar}$ at $550{ }^{\circ} \mathrm{C}$ for $5 \mathrm{~h}$. The activated catalyst was diluted with white quartz sand (50-70 mesh size) in a catalyst/sand volume ratio of 2:1 to increase the interparticle porosity and decrease the pressure drop across the reactor. Prior to SRM experiments, the catalyst was further activated in-situ at $350{ }^{\circ} \mathrm{C}$ for $1 \mathrm{~h}$ under $10 \% \mathrm{H}_{2} / \mathrm{Ar}$ environment. The Agilent $7890 \mathrm{~B}$ GC equipped with thermal conductivity detector (TCD) and flame ionization detector (FID) were used for quantitative estimation of the product gases, and collected condensate, respectively. The gaseous products were separated using Restek Shin Carbon (2 m x 2 mm x 1/8”) packed column and the cold trapped condensate was analysed with an Agilent DB-1 (60 m x $250 \mu \mathrm{m} \times 1 \mu \mathrm{m})$ capillary column with $\mathrm{He}$ as the carrier gas. The methanol conversion and selectivity towards reformate gases were evaluated using Eqs. 2-4 as follows: 
1 Conversion $_{\text {Methanol }}=\frac{\mathrm{CH}_{3} \mathrm{OH} \text { moles converted }}{\mathrm{CH}_{3} \mathrm{OH} \text { moles used }} \times 100 \%$

$2 S_{\mathrm{CO} / \mathrm{CO} 2 / \mathrm{CH} 4}=\frac{\mathrm{CO} / \mathrm{CO} 2 / \mathrm{CH} 4 \text { moles in product }}{\left(\mathrm{CO}_{2}+\mathrm{CO}+\mathrm{CH} 4\right) \text { moles } \text { in product }} \times 100 \%$

$3 \quad S_{\mathrm{H}_{2}}=\frac{\mathrm{H}_{2} \text { moles in product }}{\left(\text { moles of } \mathrm{H}_{2}+2 \mathrm{X} \text { moles of } \mathrm{CH}_{4}\right) \text { in product }} \times 100 \%$

$4 \quad 2.5$ Catalyst Stability Tests

5 Catalysts stability tests were performed with freshly reduced catalyst for continuous $40 \mathrm{~h}$

6 under the same conditions as described in section 2.4. The sand and spent catalysts were separated

7 using 300 mesh screen (150 $\mu \mathrm{m}$ opening size). The spent catalysts were subjected to various

8 characterizations such as BET, XRD and TGA-DSC.

9 3. Results and Discussion

10

4

19

\subsection{Thermal Behavior and Template Removal Analysis of M-MCM-41 Samples}

The TGA and DSC analyses were performed simultaneously to ascertain the thermal behavior of the samples. Fig. 1 shows the TGA-DSC profiles of as-synthesized pure MCM-41 and M-MCM-41 samples recorded under air.

15

6

7

18

0

1

22 

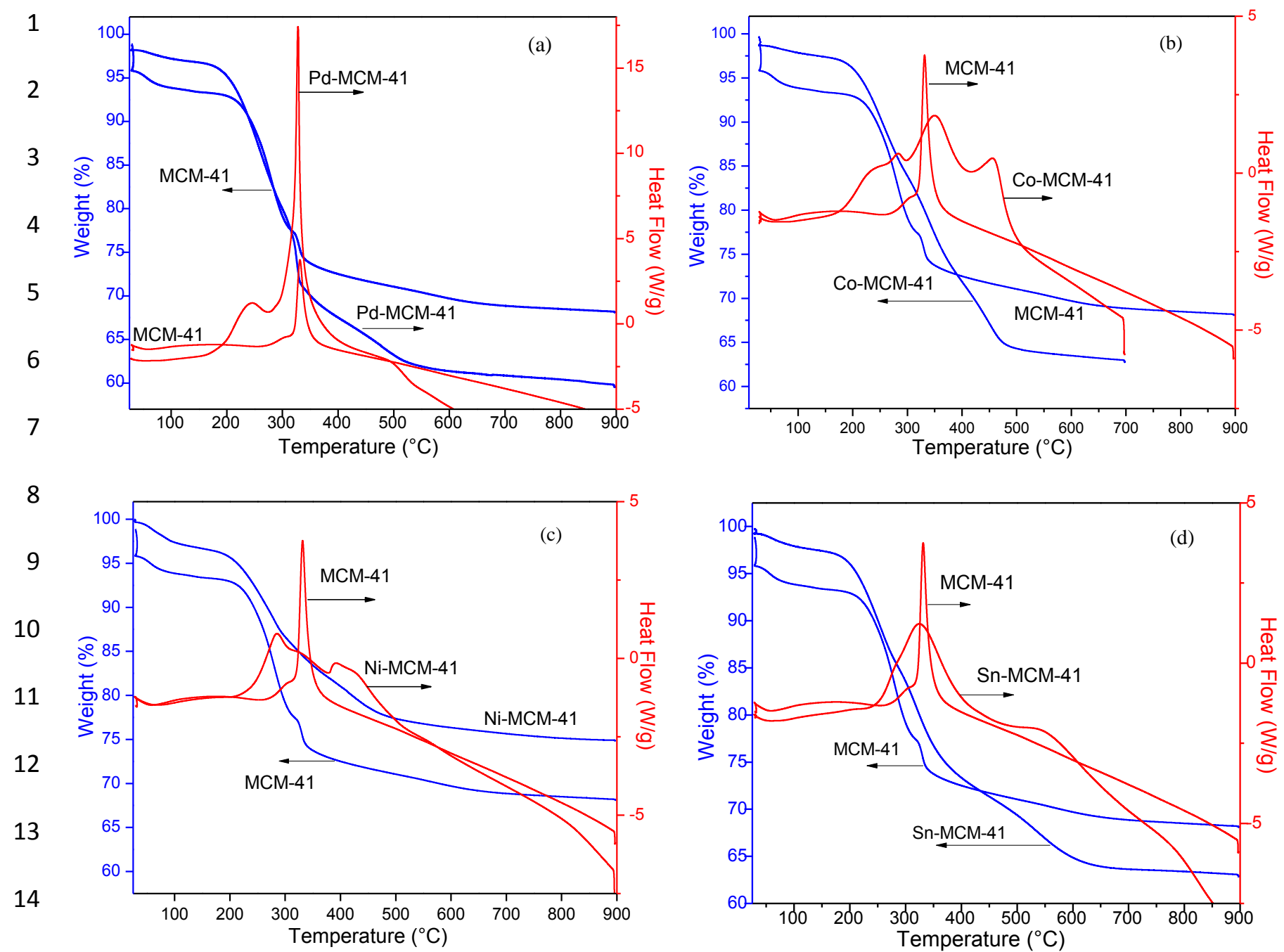

Fig. 1: TGA-DSC thermograms of as-synthesized: (a) Pd-MCM-41, (b) Co-MCM-41, (c) Ni-

19 associated with notable weight loss that can be attributed to decomposition of the template (CTAB)

20 used in MCM-41 synthesis. The weight loss before $200{ }^{\circ} \mathrm{C}$ is related to vaporization of

21 physiosorbed water and/or gas molecules on the catalyst surface. Another exothermic weight loss

22 between $200-280{ }^{\circ} \mathrm{C}$ for $\mathrm{Pd}-\mathrm{MCM}-41$ is ascribed to the decomposition of $\mathrm{Pd}\left(\mathrm{NO}_{3}\right)_{2}$ precursor and

23 traces of $\mathrm{Pd}\left(\mathrm{NH}_{3}\right)_{2}$ complex arising from $\mathrm{NH}_{3}$ used for precipitation of the sample during synthesis 
[23-25]. The Co-MCM-41 samples showed two distinct exothermic peaks apart from the strong

2 peak observed due to $\mathrm{CTAB}$ decomposition at about $350{ }^{\circ} \mathrm{C}$. The first broader thermogram

3 representing $\sim 3 \%$ gradual weight loss from $200-300{ }^{\circ} \mathrm{C}$ is ascribed to decomposition of the

4 precursor $\mathrm{CoCl}_{2} \cdot 6 \mathrm{H}_{2} \mathrm{O}$, while the second sharper peak with $\sim 5 \%$ weight loss between $450-500{ }^{\circ} \mathrm{C}$

5 is due to decomposition of $\mathrm{Co}(\mathrm{OH})_{2}$ to $\mathrm{CoO}$ in the silica matrix [26]. In the thermograms of Ni-

6 MCM-41 samples, $\sim 2 \%$ weight loss in the range of $400-500{ }^{\circ} \mathrm{C}$ could be associated with the

7 decomposition of $\mathrm{Ni}(\mathrm{OH})_{2}$. This is consistent with the observations made by Li and Liu [27] for

8 the decomposition of $\mathrm{Ni}(\mathrm{OH})_{2}$ to $\mathrm{NiO}$ between 335 and $500{ }^{\circ} \mathrm{C}$. The profile for $\mathrm{Sn}-\mathrm{MCM}-41$

9 (which had a similar thermal degradation profile as Zn-MCM-41, data not provided) showed a

10 minute weight loss at $550{ }^{\circ} \mathrm{C}$, most likely due to the presence of polymeric Sn hydroxide groups

11 which normally decompose to tin oxides at temperature $\geq 500{ }^{\circ} \mathrm{C}$ [28]. The steady minimal weight

12 loss which occurred above $600{ }^{\circ} \mathrm{C}$ for all samples could be ascribed to condensation of

13 intramolecular water molecules to form the Si-O-Si-O-Si framework [29].

\subsection{Textural Properties Evaluation of Calcined Materials}

In order to evaluate the textural properties of the catalysts, a nitrogen physiosorption

16 analysis was performed. Table 1 summarizes the textural properties of MCM-41 support, calcined

17 and spent M-MCM-41 catalysts. While pure MCM-41 showed surface area of $\sim 1039 \mathrm{~m}^{2} / \mathrm{g}$, the

18 surface areas for $10 \mathrm{wt} \%$ metal loaidngs were observed in the range of 795 to $1000 \mathrm{~m}^{2} / \mathrm{g}$, depending

on the type of metal. Usually, the addition of metal fills the pores making them inaccessible to $\mathrm{N}_{2}$

20 (adsorbate) molecules and thus decreases the surface area. The pore diameter increased slightly

21 from $3.2 \mathrm{~nm}$ to an average of $3.65 \mathrm{~nm}$ upon incorporation of the metals. This can be attributed to

22 the plugging of smaller pores by metal particles as well as interference of the formation of ordered

23 mesopores by the metal ions, which also leads to a decline in surface area. 
1 Table1: BET surface area, pore size and pore volume of calcined and spent catalysts

\begin{tabular}{|c|c|c|c|c|c|c|}
\hline $\begin{array}{c}\text { MCM41 } \\
\text { Supported } \\
\text { Catalysts }\end{array}$ & $\begin{array}{c}\text { Surface } \\
\text { Area }^{1} \\
\left(\mathrm{~m}^{2} / \mathrm{g}\right)\end{array}$ & $\begin{array}{c}\text { Surface } \\
\text { Area }{ }^{1} \\
\left(\mathrm{~m}^{2} / \mathrm{g}\right) \text { after } \\
\text { 40h Reaction }\end{array}$ & $\begin{array}{l}\text { Pore } \\
\text { Size }^{2} \\
(\mathbf{n m})\end{array}$ & $\begin{array}{c}\text { Pore Size }^{2} \\
\text { (nm) after } \\
\text { 40h } \\
\text { Reaction }\end{array}$ & $\begin{array}{c}\text { Pore } \\
\text { Volume } \\
\left(\mathrm{cm}^{3} / \mathrm{g}\right)\end{array}$ & $\begin{array}{l}\text { Pore Volume } \\
\left(\mathrm{cm}^{3} / \mathrm{g}\right) \text { after } \\
\text { 40h Reaction }\end{array}$ \\
\hline MCM-41 & 1039.2 & - & 3.2 & - & 0.75 & - \\
\hline Ni-MCM-41 & 824.6 & 543.0 & 3.8 & 3.7 & 0.84 & 0.76 \\
\hline Cu-MCM-41 & 795.7 & 444.4 & 3.7 & 3.6 & 0.62 & 0.42 \\
\hline Pd-MCM-41 & 1078.8 & 729.4 & 3.5 & 3.5 & 0.82 & 0.56 \\
\hline Sn-MCM-41 & 1009.3 & 668.2 & 3.3 & 3.2 & 0.77 & 0.51 \\
\hline Co-MCM-41 & 815.8 & 447.1 & 3.6 & 3.8 & 0.79 & 0.66 \\
\hline Zn-MCM-41 & 800.3 & 494.1 & 3.5 & 2.6 & 0.62 & 0.39 \\
\hline
\end{tabular}

2

The total pore volume varied from $0.619-0.843 \mathrm{~cm}^{3} / \mathrm{g}$, indicating differences in the pore volume and shapes of the mesopores.The $\mathrm{N}_{2}$ adsorption-desorption isotherms of all the catalysts in Fig. 2 show a typical type IV isotherm and H1 hysteresis loop (based on the empirical IUPAC classification) which are indicative of mesoporous materials. The point of inflection at relative pressure of $\left(\mathrm{P} / \mathrm{P}_{0}=0-0.2\right)$ represents the completion of monolayer coverage by $\mathrm{N}_{2}-$ adsorbate. The uptake in $\mathrm{N}_{2}$ adsorption from $\mathrm{P} / \mathrm{P}_{0}=0.2-0.4$ corresponds to $\mathrm{N}_{2}$ condensation within the ordered mesopores of the MCM-41 framework. The steepness of this step $\left(\mathrm{P} / \mathrm{P}_{0}=0.2-0.4\right)$ emphasizes the narrow ordered pore size distribution of the MCM-41. It is worth noting that the steepness decreased upon incorporation of metals, suggesting some loss of the ordered structure upon metal addition. The plateau at high relative pressures $\left(\mathrm{P} / \mathrm{P}_{0}=0.4-0.85\right)$ is attributed to the multilayer $\mathrm{N}_{2}$ adsorption. Finally, the sharp $\mathrm{N}_{2}$ adsorption at higher relative pressues $\left(\mathrm{P} / \mathrm{P}_{0}>0.9\right)$ associated with a small hysteresis loop is usually ascribed to $\mathrm{N}_{2}$ condensation in the interparticle pores [30]. 


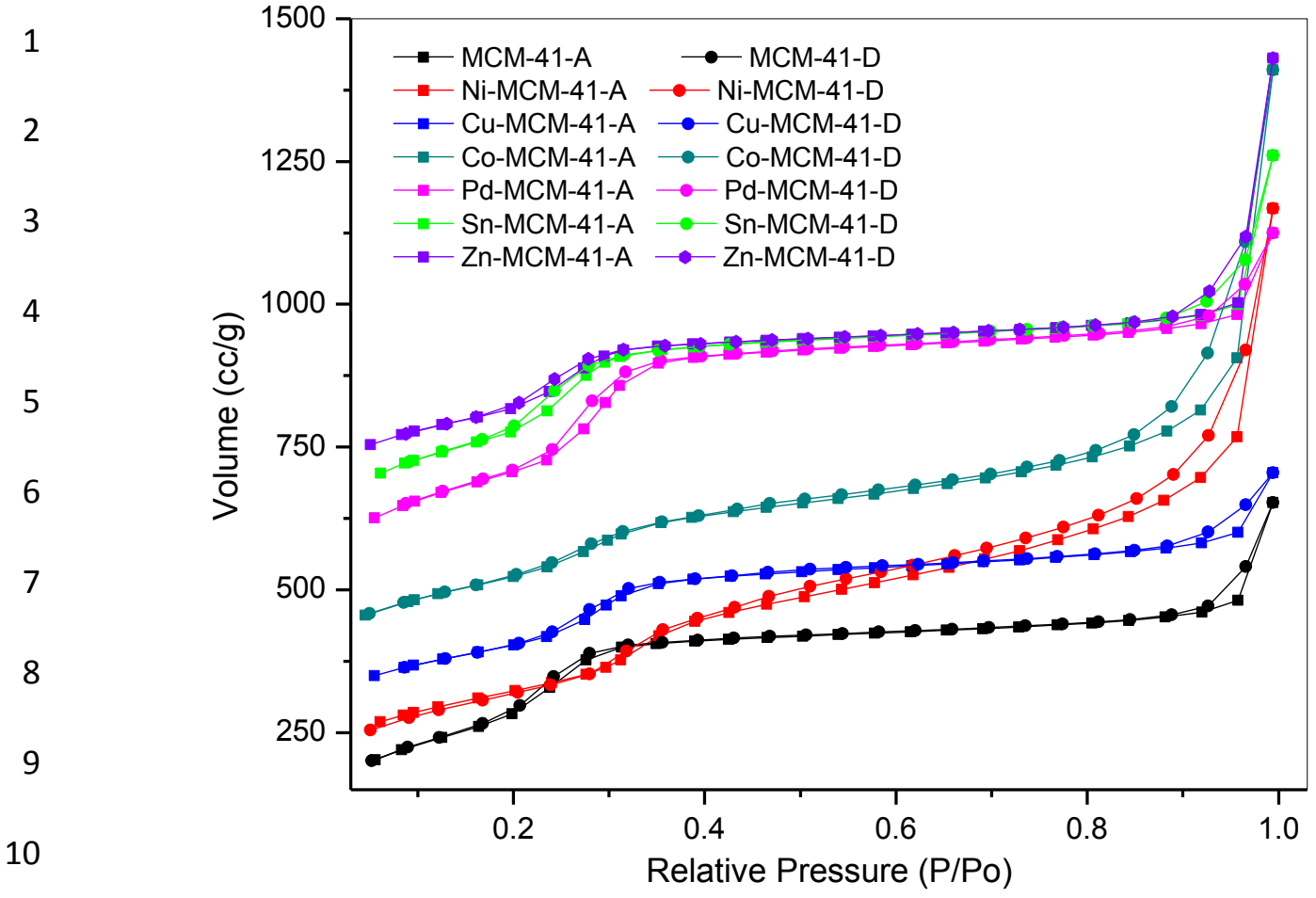

Fig. 2: $\mathrm{N}_{2}$ adsorption-desorption isotherms of M-MCM-41 catalysts

\subsection{Powder X-ray Diffraction Studies of Calcined Materials}

The powder XRD method was used for structural phase identification, determination of lattice parameters such as the crystallite sizes and evaluation of changes in the shapes and sizes of the ordered mesopores. Fig. 3(a) shows the small angle powder XRD spectra of calcined M-MCM41 catalysts. The mesoporous structures of M-MCM-41 samples inferred by the $\mathrm{N}_{2}$ physisorption

17 isotherms in Fig. 2 are consistent with the XRD studies. The variations in the XRD peak intensities and positions due to different metals are clearly observed in Fig. 3(a). While the XRD spectra of pure MCM-41 and Pd-MCM-41 showed intense resolved diffraction peaks, Zn-MCM-41 showed least intensity peak; in $2 \theta$ value range of $\sim 1.5-2.5^{\circ}$, which could be indexed to (100) reflections. Additionally, two low intensity peaks for (110) and (200) reflections centered at $\sim 4.4^{\circ}$ and $\sim 5.2^{\circ}$, respectively, were observed only for MCM-41 and Pd-MCM-41. Since the catalysts are prepared 
1 using one-pot method, the decreased order of MCM-41 upon metal addition indicates that the metal

2 ion could be interfering with ordered structure formation during the synthesis.

3

4

5
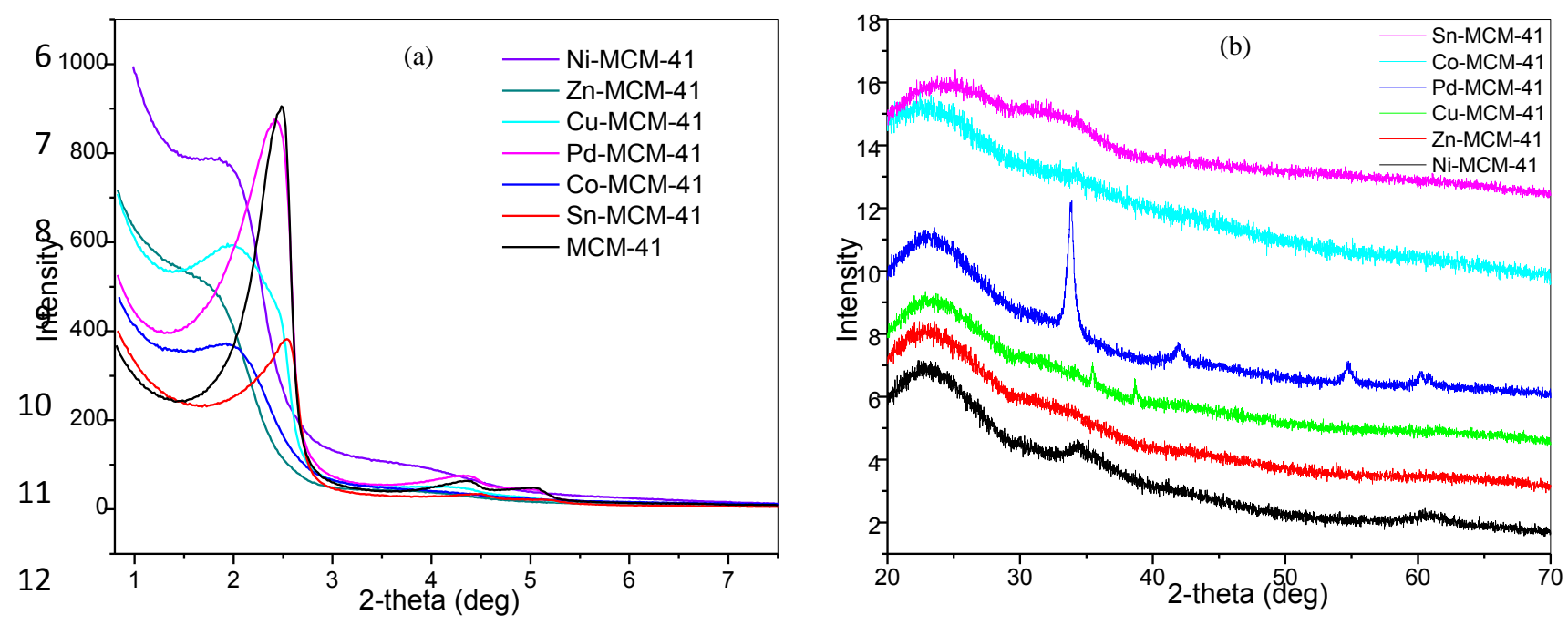

13

Fig. 3: (a) SAXRD, and (b) WAXRD patterns of calcined M-MCM-41catalysts

15 The results shown in Fig. 3 (a) also suggest that the extent of this influence is different for different

16 metals on the MCM-41 structure. For example, while Pd showed no effect on mesoporous

17 structure, $\mathrm{Zn}$ affected it the most. The relatively intense peaks of Pd-MCM-41 and Sn-MCM-41

18 suggest that they are comparatively the most ordered mesoporous catalysts, and consequently

19 exhibited the exceptionally high surface areas showed by BET analysis (Table 1). The peak

20 intensities of Co-, $\mathrm{Zn}-, \mathrm{Cu}$ - and Ni-MCM-41 catalysts were much broader and weaker, and shifted

21 towards a lower $2 \theta$ value. While the weaker intensities implied the loss of some degree of ordered

22 structure, the lower angle shift indicated an increase in pore sizes. This observation corroborates

23 our inference that the sharpness of the pore filling step $\left(\mathrm{P} / \mathrm{P}_{0}=0.2-0.4\right)$ of the $\mathrm{N}_{2}$ sorption isotherm 
1 (Fig. 2) decreases with metal addition due to significant decline in the long range order of the

2 MCM-41 framework (Fig. 3a).

The wide angle X-ray diffraction patterns of the calcined M-MCM-41 catalysts are shown

4 in Fig. 3 (b). The XRD spectra of Cu-MCM-41 samples exhibited two weak diffraction peaks at

$52 \theta$ values around $35.6^{\circ}$ and $38.9^{\circ}$ attributed to the $\mathrm{CuO}$ crystallites phase (JCPDS 80-1917). PdO-

6 crystallites exhibited intense diffraction peak centered at $2 \theta$ value of $33.9^{\circ}$ indexed to (101)

7 reflections, followed by weaker difractions at $42.3^{\circ}, 55^{\circ}, 61.1^{\circ}$ and $72.1^{\circ}$ indexed to (110), (112),

8 (200), and (211) reflections (JCPDS 75-584), respectively [31]. The remarkably intense diffraction

9 peaks observed for Pd-MCM-41 could be due to large electron density of $\mathrm{Pd}[32,33]$. The crystal

10 sizes of $\mathrm{CuO}$ and $\mathrm{PdO}$ calculated by the Scherrer's equation are $14.2 \mathrm{~nm}$ and $15.8 \mathrm{~nm}$, respectively.

11 No discernible diffraction peaks are observed for oxides of $\mathrm{Sn}, \mathrm{Ni}$, Co and $\mathrm{Zn}$. This can be

12 attributed to three possibilities: (i) the nanocyratalline oxides are embedded in the pore walls of

13 the matrix, hence insufficiently exposed and thereby minimizing diffractions, (ii) nanocrystalline

14 nature of the particles; making them x-ray amorphous, and (iii) preferential orientation of the metal

15 particles in the MCM-41 matrix resulting in little or no diffractions.

16 3.4. SEM-EDX Analysis

17 SEM-EDX analysis was carried out to examine the distribution of metals in MCM-41

18 framework. Fig. 4 shows the EDX-SEM elemental mapping of the catalysts. A close examination

19 of the images reveal that $\mathrm{Cu}, \mathrm{Pd}, \mathrm{Sn}$ and $\mathrm{Zn}$ particles (red dots) were highly dispersed throughout

20 the MCM-41 framework (gray background). On the other hand, Co and Ni particles were

21 comparatively less dispersed in the support and showed signs of agglomeration. A uniform

22 distribution of the metal particles bolsters stability by retarding catalyst deactivation caused via 23 metal particles sintering. 

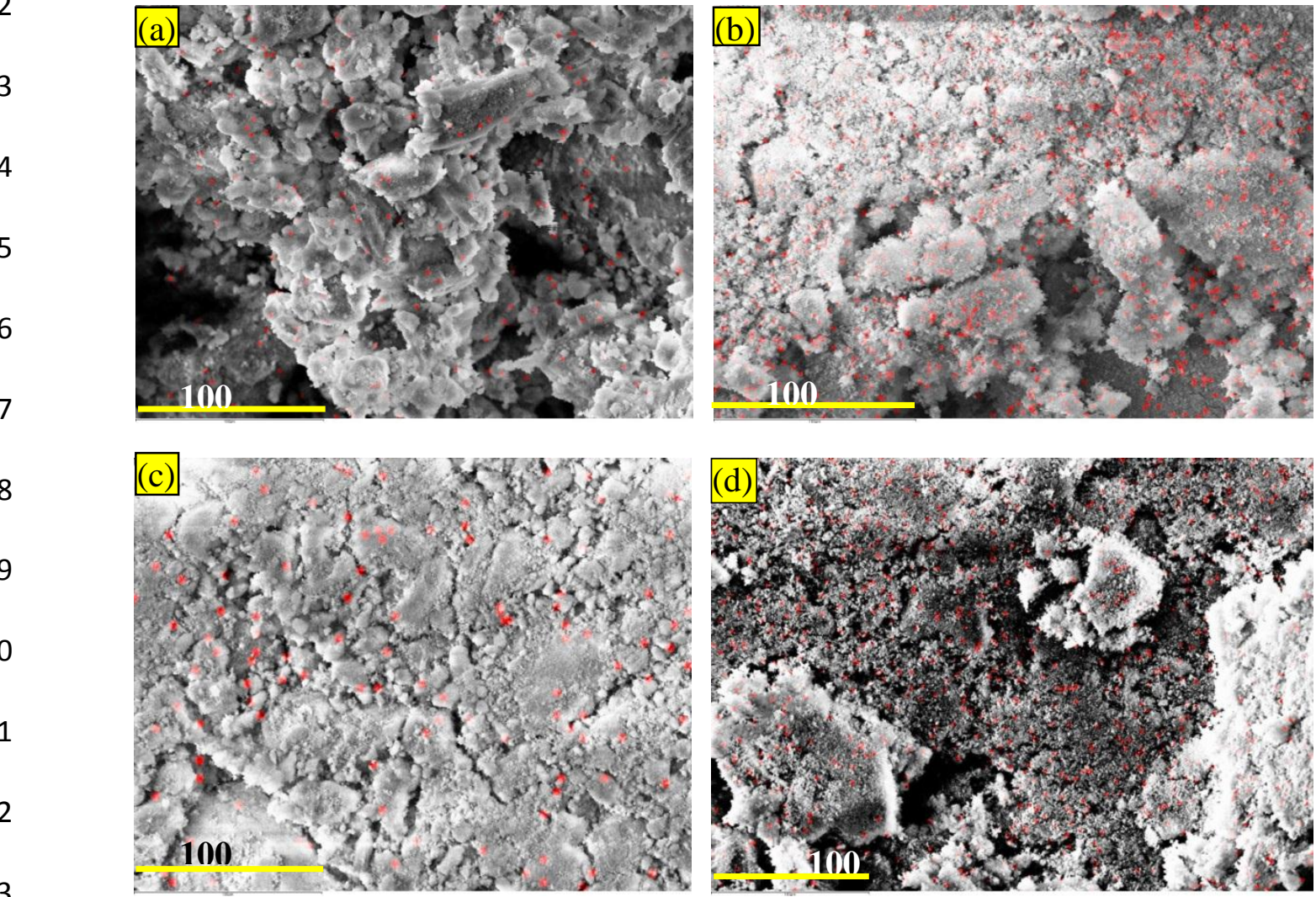

\section{4}
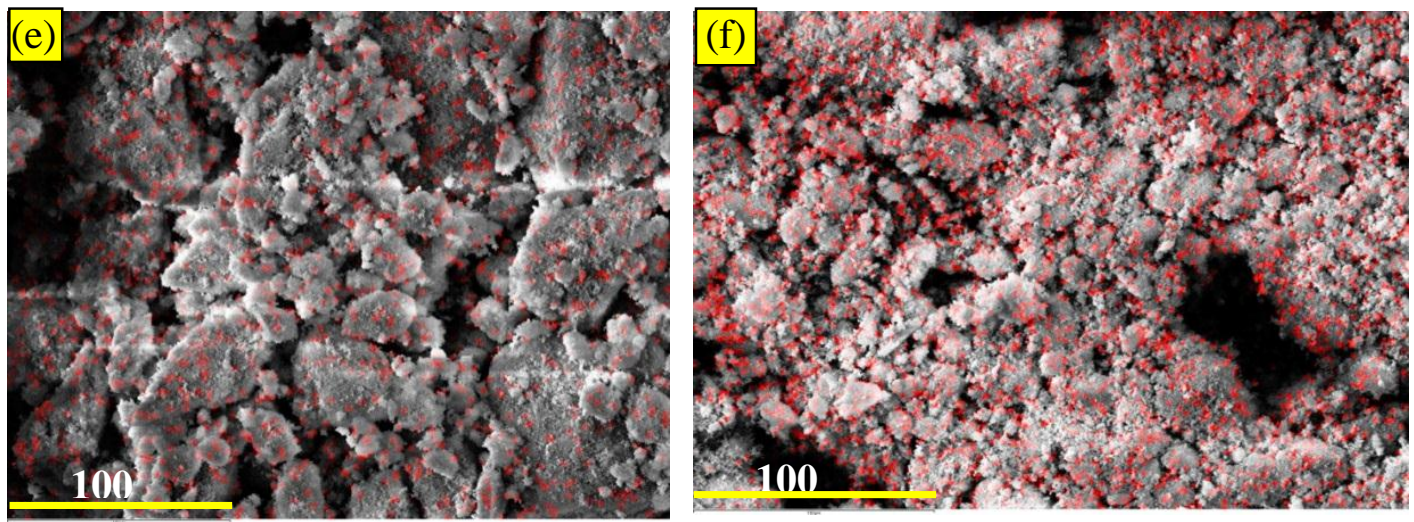

Fig. 4: EDX-SEM elemental mapping of MCM-41 catalysts (Red Dots): (a) Co, (b) Cu, (c) Ni, (d) Pd, (e) Sn, and (f) $\mathrm{Zn}$

\subsection{Tranmission Electron Microscopic Imaging}

TEM imaging was performed to corroborate the BET and XRD results, and to obtain an

24 approximate value of the pore and metal particle sizes of the calcined catalysts. Fig. 5(a) and (b) 
1 show the typical high resolution TEM images of the calcined pure MCM-41 and Pd-MCM-41,

2 respectively.

3

4

5

6

7

8

9

10

11

12

13

14

15

16

17

18

19

20

21

22

23
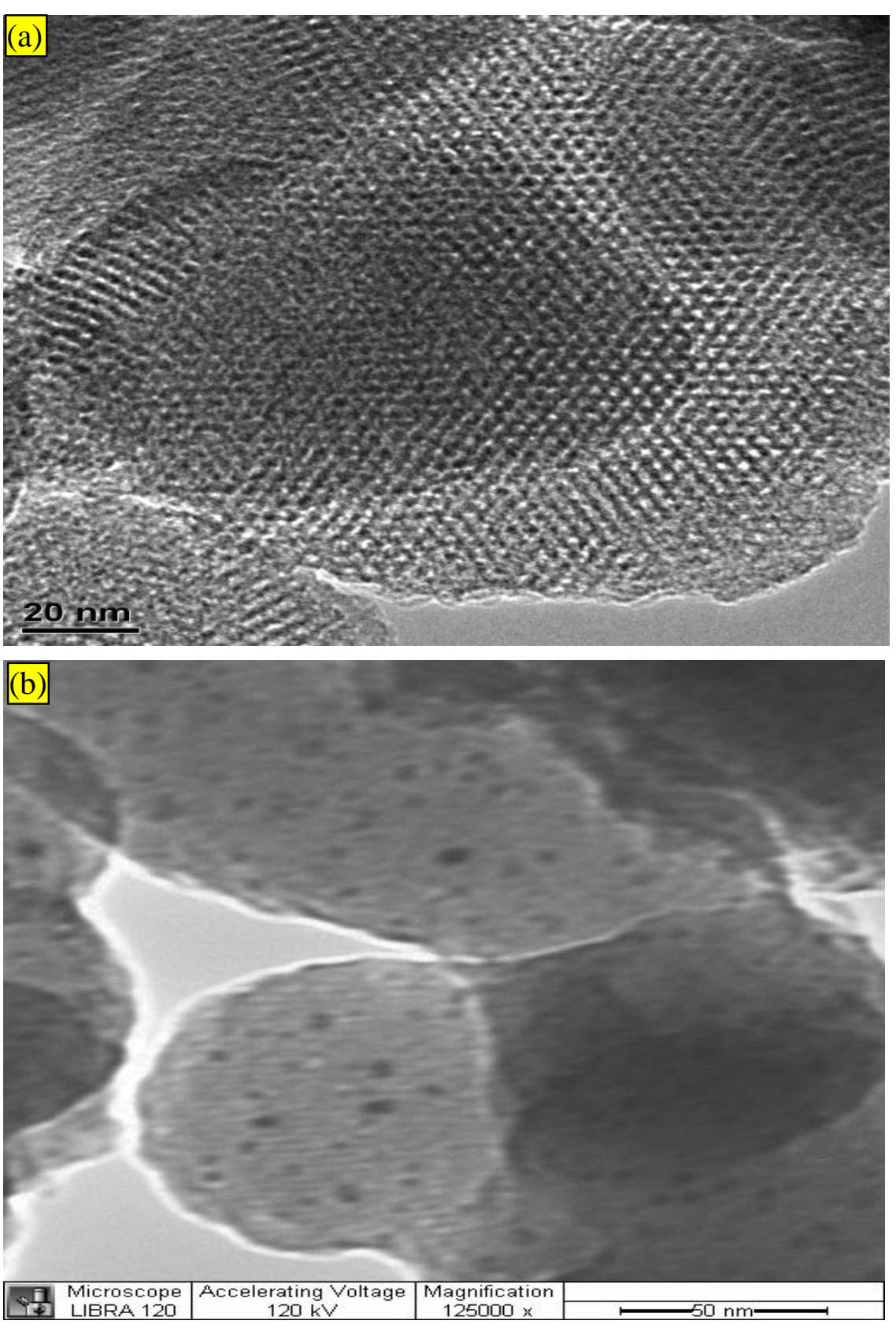

Fig. 5: TEM images of calcined: (a) MCM-41, and (b) Pd-MCM-41 (Pd-black dots)

The uniformly ordered hexagonal pores of MCM-41 evident in the TEM images are consistent with the results of our SAXRD studies discussed previously. The uniform distribution of the Pd 
nanoparticles (black/darker dots) in the MCM-41 framework is conspicuous in the TEM image in

2 Fig. 5(b). Further, the experimental metal loading, determined using ICP-OES and EDX analysis

3 (next section) is consistent with theoretical loading and indicate that our optimized one-pot

4 synthesis can be a reliable method for uniform incorporation of metal oxides in MCM-41. The

5 distance between pores is about 3-4 nm, while the bulk catalyst particle sizes were estimated to

6 be in the range of $2.5-60 \mu \mathrm{m}$.

$7 \quad$ 3.6. ICP-OES and EDX Spectroscopy

ICP-OES and EDX were used to estimate the actual quantity of metals retained in the

9 calcined samples of MCM-41 catalysts (Table 2).

10 Table 2: Results of monometallic catalysts loading evaluated by ICP-OES and EDX analysis

\begin{tabular}{lccc}
\hline Catalyst & $\begin{array}{l}\text { Intended Metal } \\
\text { Loading }(\text { wt \%) }\end{array}$ & $\begin{array}{l}\text { Metal Loading using } \\
\text { ICP (wt \%) }\end{array}$ & $\begin{array}{l}\text { Metal Loading using } \\
\text { EDX (wt \%) }\end{array}$ \\
\hline Ni-MCM-41 & 10 & 13.8 & 11.1 \\
Cu-MCM-41 & 10 & 8.2 & 8.2 \\
Pd-MCM-41 & 10 & 2.5 & 3.6 \\
Sn-MCM-41 & 10 & 13.4 & 14.1 \\
Co-MCM-41 & 10 & 13.2 & 10.5 \\
Zn-MCM-41 & 10 & 9.9 & 11.7 \\
\hline
\end{tabular}

11

12 The metal loadings determined experimentally were fairly consistent with the theoretical loading

13 except in the case of Pd-samples. We believe this difference was possibly caused by incomplete

14 precipitation of $\mathrm{Pd}$ (as hydroxides $\left[\mathrm{Pd}(\mathrm{OH})_{2}\right]$ ) in the mesoporous matrix or possibly due to

15 adventitious loss of metals during the washing step of the catalyst preparation.

\subsection{FTIR Spectra Analysis}


2 MCM-41 matrix were monitored using FTIR spectroscopy. The typical FTIR spectra of as

3 prepared MCM-41 and calcined M-MCM-41 are shown in Fig. 6(a).

4 The FTIR peak at $\sim 1500 \mathrm{~cm}^{-1}$ is assigned to aliphatic $\mathrm{C}-\mathrm{H}$ bending vibrations while those

5 peaks in the range of $2600-3100 \mathrm{~cm}^{-1}$ are assigned to aliphatic $\mathrm{C}-\mathrm{H}$ stretching vibrations of the

6 surfactant (CTAB) in the as-prepared (non-calcined) MCM-41 support [34]. Consequently, these

7 peaks disappear in the calcined samples implying that the calcination at $550{ }^{\circ} \mathrm{C}$ effectively removed

8 all the surfactant from MCM-41 matrix as expected. The wide absorption band between 3600 and

$93200 \mathrm{~cm}^{-1}$ could be due to the $\mathrm{O}-\mathrm{H}$ bond stretching vibrations of silanol groups and/or adsorbed

10 moisture on the support [35]. The intense nature of the O-H peak of the as-prepared samples

11 compared to calcined samples portrays the presence of numerous $-\mathrm{OH}$ groups in the matrix that 12 are present under synthesis conditions.
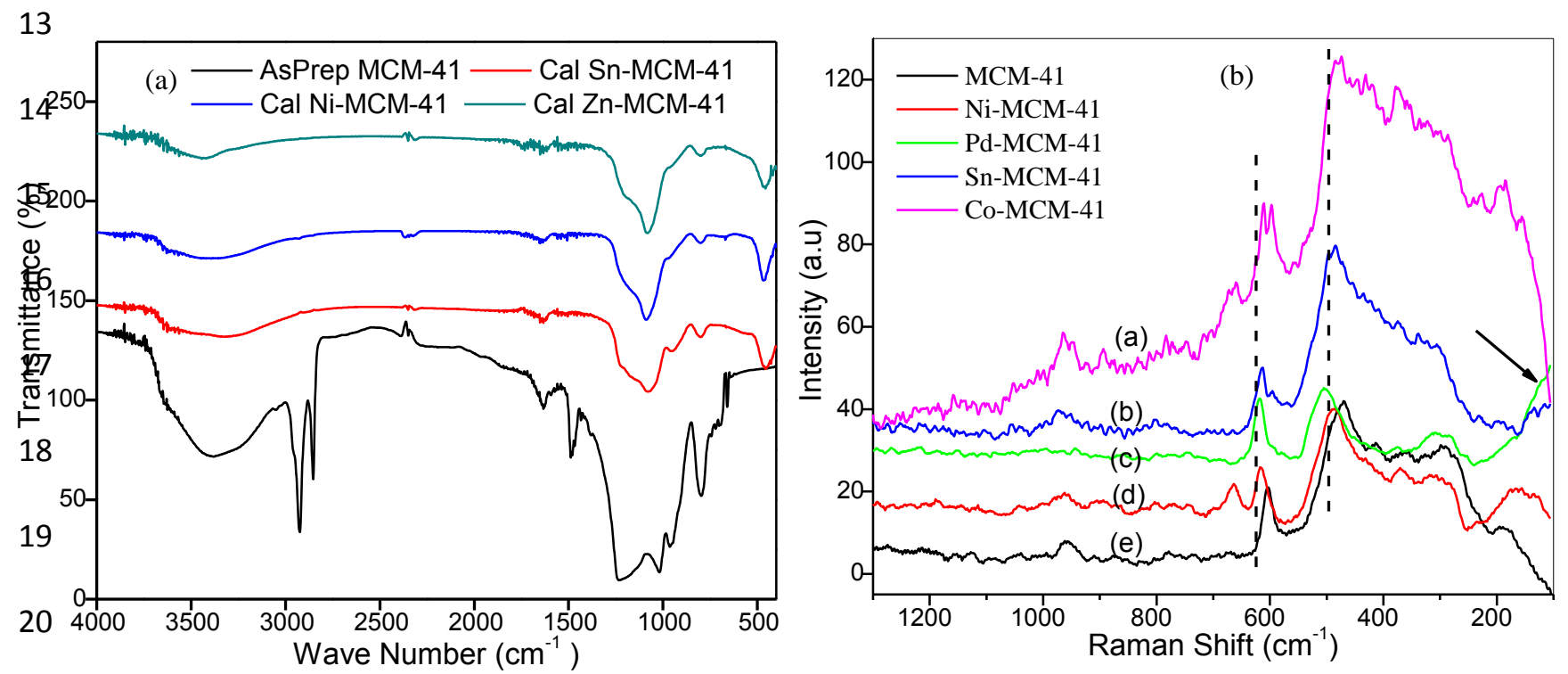

21

Fig. 6: Typical (a) FTIR and (b) Raman spectra of calcined M-MCM-41catalysts

The bands at $1650 \mathrm{~cm}^{-1}$ are caused by bending vibrations of entrapped water molecules in the

24 MCM-41 matrix, and those observed between $800 \mathrm{~cm}^{-1}$ and $1000 \mathrm{~cm}^{-1}$ are assigned to bending and 
1 symmetric stretching vibrations of the Si-O-Si linkages [35, 36]. The bands observed around 1250

$2 \mathrm{~cm}^{-1}$ and $1030 \mathrm{~cm}^{-1}$ are characteristic peaks of asymmetric Si-O-Si stretching vibrations [21, 37].

3 The conspicuous absorption peaks around $500 \mathrm{~cm}^{-1}$, present only when the metals were

4 incorporated in the silica support, could be ascribed to the bending vibrations of tetragonal Si-O-

5 Si- bonds [38].

\section{$6 \quad$ 3.8. Laser Raman (LR) Spectra Analysis}

The oxides of transition metals are well studied for their strong inelastic Raman scattering

8 due to their inherent molecular symmetry [39]. The Raman technique was therefore used to record

9 vibrational low-frequency modes of the encapsulated metals in the silica framework as a complementary method to the FTIR spectroscopy. The IR active stretching vibrations of surface

11 silanol groups between 3000 and $4000 \mathrm{~cm}^{-1}$ and absorption bands around $1600 \mathrm{~cm}^{-1}$ were Raman

12 inactive hence not shown. The Raman spectra of M-MCM-41 catalysts in the range of 100-1300

$13 \mathrm{~cm}^{-1}$ are shown in Fig. 6(b). The intense IR signals due to Si-O-Si bending and stretching 14 vibrations at $800 \mathrm{~cm}^{-1}$ and $1000 \mathrm{~cm}^{-1}$ (Fig. 6(a)) showed very weak Raman bands. The intense 15 Raman bands at $600 \mathrm{~cm}^{-1}$ and $490 \mathrm{~cm}^{-1}$ are attributed to the $\mathrm{Si}-\mathrm{O}-\mathrm{Si}$ vibrations of amorphous three 16 membered $\mathrm{SiO}_{4}$ and the four membered tetrahedral $\mathrm{SiO}_{4}$ rings, respectively [40-42]. The presence 17 of free surface silanols is revealed by band at $960 \mathrm{~cm}^{-1}$ attributed to the $\mathrm{Si}-\mathrm{OH}$ stretching vibrations 18 [41]. A slight redshift of about $10-30 \mathrm{~cm}^{-1}$ was noticed for both bands upon incorporation of the metals in the MCM-41 framework. These nominal shifts could be due to an appreciable decrease 20 in the bond strength and/or bond angle caused by the formation of oxygen-metal-oxygen (O-M-

21 O) bridges in the silica framework [43]. This observation suggest possible modifications in the

22 MCM-41 structure induced by the metal presence.

23 3.9. $\mathrm{H}_{2}$-TPR Studies of Metal-Support Interactions and Reducibility of Calcined Samples 

strength of metal-support interactions, specifically between the metal oxides and the support as well as determining the ease of reducibility of the metal oxides (Hurst et al [44] ). The TPR profiles

4 in $10 \% \mathrm{H}_{2} / \mathrm{Ar}$ of M-MCM-41 catalysts calcined at $550{ }^{\circ} \mathrm{C}$ are shown in Fig. 7.

5

6

7

8

9

10

11

12

13

14

15

16

17

18

19

20

21

22

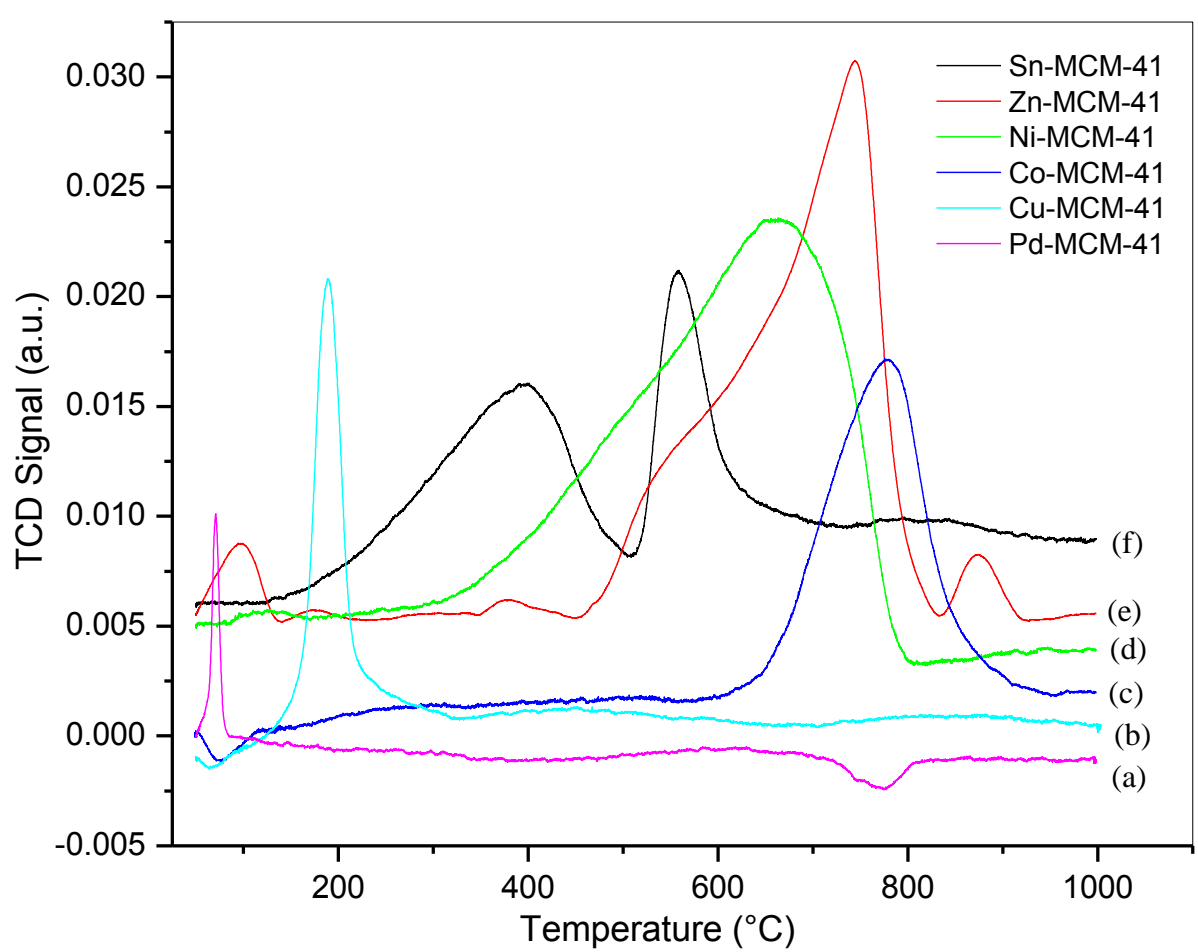

Fig. 7: $\mathrm{H}_{2}$-TPR profiles of M-MCM-41 catalysts: (a) $\mathrm{Pd}$, (b) $\mathrm{Cu}$, (c) $\mathrm{Co}$, (d) Ni, (e) $\mathrm{Zn}$, and (f) $\mathrm{Sn}$ The reduction of $\mathrm{CuO}$ to $\mathrm{Cu}^{0}$ began at $100{ }^{\circ} \mathrm{C}$ and attained a maximum peak at $200{ }^{\circ} \mathrm{C}$. This concurred with observation reported by Matsumura and Vizcaino et al $[45,46]$, wherein $\mathrm{Cu}$ supported on commercial silica and ZSM were investigated for their methanol and ethanol steam reforming activities, respectively. They ascertained that reduction of $\mathrm{CuO}$ to $\mathrm{Cu}^{0}$ occurred in a similar temperature range. Nonetheless, the fact that the bulk $\mathrm{CuO}$ was reduced in the temperature range of $200{ }^{\circ} \mathrm{C}<\operatorname{Tr}<300{ }^{\circ} \mathrm{C}$ [47-49], suggests that the relatively lower $\mathrm{Cu}$ reduction temperature 
1 of our sample was caused by good dispersion of relatively small sizes of the $\mathrm{CuO}$ crystallites as

2 evident in the EDX mapping discussed before.

The TPR of Pd-MCM-41 sample (Fig. 7) showed the greatest ease of reducibility among

4 the synthesized catalysts. A sharp peak for hydrogen consumption that can be ascribed to PdO

5 reduction was noticed at $\sim 95{ }^{\circ} \mathrm{C}$ followed by a small negative peak at $\sim 780{ }^{\circ} \mathrm{C}$ ascribed to the

6 hydrogen release confirming the inherent ability of palladium to strongly absorb hydrogen inside

7 the interstitial cavities of the metal lattice (face-centered cubic structure) to form polymorphs of

8 palladium hydride [50]. The observed TPR profile of PdO is similar to that obtained by Chou et al

9 [51]. At lower temperatures $\left(<100^{\circ} \mathrm{C}\right)$, palladium crystallites extract hydrogen atoms to form the

10 beta PdH phases which decomposes spontaneously (and desorb the hydrogen atoms) at

11 temperatures $>633{ }^{\circ} \mathrm{C}$ to form the alpha $\mathrm{PdH}$ phase. They also reported that the reduction

12 temperature of bulk PdO species under hydrogen stream is generally low $\left(-100{ }^{\circ} \mathrm{C}<\operatorname{Tr}<60^{\circ} \mathrm{C}\right)$.

13 In contrast to $\mathrm{PdO}$, reduction of $\mathrm{NiO}$ to $\mathrm{Ni}^{0}$ occurred in a slow progressive pattern between 300

14 and $900{ }^{\circ} \mathrm{C}$. The broadness of the peak suggested that the $\mathrm{NiO}$ crystallites had different sizes which

15 interacted differently with the support leading to hydrogen consumption over wide range of 16 temperature [52].

While the metal-support interactions have been well established in catalysts with reducible

18 supports (e.g. $\left.\mathrm{TiO}_{2}\right)[53,54]$, for inert supports (e.g. $\mathrm{SiO}_{2}$ ) several contradictory studies have been

19 reported claiming presence and absence of metal-support interactions [14, 54-59]. Furthermore,

20 most of studies indicated that the presence of metal support interactions in $\mathrm{SiO}_{2}$ supported

21 catalysts were limited to only few metals, especially, $\mathrm{Co}, \mathrm{Ni}, \mathrm{Pt}$ and $\mathrm{Pd}$. The formation of non- or

22 high temperature reducible surface compounds such as nickel silicides, cobalt silcates, Pt silicides, 23 and Pd silicides were mainly attributed to the metal-support interactions [57-60]. For Ni-MCM- 
141 , in this study, most of the $\mathrm{NiO}$ is reduced above $550{ }^{\circ} \mathrm{C}$ with reduction peak centered at $\sim 650$

$2 \quad{ }^{\circ} \mathrm{C}$. This is consistent with reported studies where lower temperature reduction part is attributed to

3 smaller $\mathrm{NiO}$ particles and the major peak centered at $\sim 650{ }^{\circ} \mathrm{C}$ corresponds to reduction of $\mathrm{Ni}$

4 silicides [18, 30]. Similar to Ni-MCM-41, Co-MCM-41 is also reduced at temperature centered at

$5780{ }^{\circ} \mathrm{C}$, indicating the possible formation of cobalt silicates which are known to be reduced at

6 inordinately higher temperatures [61, 62]. It should be noted that Ni-MCM-41 and Co-MCM-

7 41both showed least dispersion (Fig. 4) compared to other MCM-41 catalysts and $\mathrm{Ni}-\mathrm{TiO}_{2}$ and

$8 \mathrm{Co}^{-\mathrm{TiO}_{2}}$ catalysts in our earlier study [53]. The noticeable better dispersion of $\mathrm{Ni}$ and $\mathrm{Co}$ in $\mathrm{TiO}_{2}$

9 was attributed to better metal-support interactions. More specifically, we observed complete

10 reduction of $\mathrm{NiO}$ in $\mathrm{Ni}-\mathrm{TiO}_{2}$ catalysts by $600{ }^{\circ} \mathrm{C}$ with main peak centered at just $400{ }^{\circ} \mathrm{C}$ [49]. This

11 is much lower than that observed with the $\mathrm{SiO}_{2}$ matrix. The significant shift in reduction

12 temperature for $\mathrm{Ni}^{-\mathrm{TiO}_{2}}$ catalysts was attributed to metal-support interactions between $\mathrm{NiO}$ and

$13 \mathrm{TiO}_{2}$. Thus, it can be inferred that the metal-support interaction is more complex and may not be

14 determined only on the basis of surface compound formation that are reduced at high temperature.

In contrast to Co-MCM-41, Sn-MCM-41 registered two distinct hydrogen uptake peaks

16 centered at about $400{ }^{\circ} \mathrm{C}$ and $570{ }^{\circ} \mathrm{C}$ which could be ascribed to the reduction of $\mathrm{SnO}_{2}$ and $\mathrm{SnO}$

17 nanocrytallites, respectively [19]. $\mathrm{ZnO}$ exhibited three distinct reduction phases. The reduction

18 temperature of bulk $\mathrm{ZnO}$ particles is reported around $650{ }^{\circ} \mathrm{C}[63,64]$. The small reduction peak

19 around $100{ }^{\circ} \mathrm{C}$ could therefore be attributed to few nanocrystalline bulk $\mathrm{ZnO}$ particles. The more

20 intense peak at $750{ }^{\circ} \mathrm{C}$ is due to reduction of the majority of bulk $\mathrm{ZnO}$ species. The small peak

21 centered at $\sim 850{ }^{\circ} \mathrm{C}$ may be ascribed to reduction of small amounts of very stable silicates in the

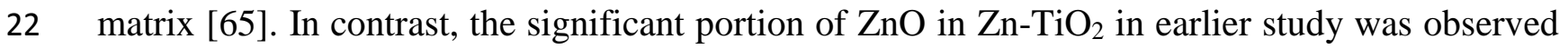

23 to be reduced in the temperature range of $300-500{ }^{\circ} \mathrm{C}$ [53] owing to better metal-support 
1 interaciton. Thus, the observation of typical reduction profile of Zn-MCM-41 indicates the absence

2 of any significant metal-support inteactions between $\mathrm{ZnO}$ and $\mathrm{SiO}_{2}$. 41 (M-MCM-41), steam reforming of methanol was carried out under identical operating conditions. Methanol conversion and selectivity to $\mathrm{H}_{2}, \mathrm{CO}, \mathrm{CO}_{2}$ and $\mathrm{CH}_{4}$ were measured for each

M-MCM-41 catalyst at four selected temperatures, 200, 250, 300 and $350{ }^{\circ} \mathrm{C}$. In our experiments, no intermediate products such as formic acid, formaldehyde, dimethyl ether or methyl formate

Methanol Decomposition: $\mathrm{CH}_{3} \mathrm{OH} \rightarrow 2 \mathrm{H}_{2}+\mathrm{CO} \Delta \mathrm{H}=90.6 \mathrm{~kJ} / \mathrm{mol}$

Water Gas Shift Reaction: $\mathrm{CO}+\mathrm{H}_{2} \mathrm{O} \leftrightarrow \mathrm{H}_{2}+\mathrm{CO}_{2} \Delta \mathrm{H}=-41.2 \mathrm{~kJ} / \mathrm{mol}$

Overall Reaction:

$$
\mathrm{CH}_{3} \mathrm{OH}+\mathrm{H}_{2} \mathrm{O} \rightarrow 3 \mathrm{H}_{2}+\mathrm{CO}_{2} \Delta \mathrm{H}=49.5 \mathrm{~kJ} / \mathrm{mol}
$$

Methanation Reaction: $\quad \mathrm{CO}+3 \mathrm{H}_{2} \rightarrow \mathrm{CH}_{4}+\mathrm{H}_{2} \mathrm{O} \Delta \mathrm{H}=-206 \mathrm{~kJ} / \mathrm{mol}$

Table 3 shows methanol conversion and product selectivity of the SRM by each catalyst. As expected for an endothermic reaction, methanol conversion increased with increase in temperature for each M-MCM-41 catalyst.

Table 3: Methanol conversion and product gas selectivities of M-MCM-41 supported catalysts

\begin{tabular}{ccccccc}
\hline Catalyst & Temperature & Conversion & \multicolumn{4}{c}{ Selectivity (\%) } \\
\cline { 4 - 6 }$\left({ }^{\mathbf{0}} \mathbf{C}\right)$ & $(\boldsymbol{\%})$ & $\mathbf{H}_{\mathbf{2}}$ & $\mathbf{C O}$ & $\mathbf{C O}_{\mathbf{2}}$ & $\mathbf{C H}_{\mathbf{4}}$ \\
\hline \multirow{3}{*}{ Co-MCM-41 } & 200 & 6.4 & 99.1 & 21.3 & 69.0 & 9.7 \\
& 250 & 12.1 & 98.9 & 18.0 & 77.5 & 4.5 \\
& 300 & 14.4 & 98.2 & 28.4 & 63.6 & 8.0 \\
\hline \multirow{3}{*}{ Pd-MCM-41 } & 350 & 38.2 & 96.2 & 44.7 & 44.6 & 10.7 \\
& 200 & 46.4 & 99.2 & 93.5 & 5.7 & 0.8 \\
& 250 & 51.9 & 97.8 & 77.3 & 18.0 & 4.7 \\
\hline
\end{tabular}




\begin{tabular}{lcccccc}
\hline & 350 & 73.4 & 98.4 & 69.4 & 24.5 & 6.1 \\
\hline \multirow{3}{*}{ Zn-MCM-41 } & 200 & 15.7 & 91.9 & 35.6 & 40.8 & 23.6 \\
& 250 & 18.6 & 94.9 & 34.1 & 52.5 & 13.4 \\
& 300 & 35.6 & 98.5 & 28.5 & 55.1 & 16.4 \\
Cu-MCM-41 & 350 & 47.4 & 98.6 & 15.3 & 61.2 & 23.5 \\
& 200 & 53.9 & 100 & 4.2 & 95.8 & 0 \\
& 250 & 67.8 & 100 & 5.6 & 94.4 & 0 \\
Sn-MCM-41 & 300 & 69.9 & 100 & 16.4 & 83.6 & 0 \\
& 350 & 82.3 & 99.5 & 17.7 & 81.3 & 1.0 \\
\hline \multirow{3}{*}{ Ni-MCM-41 } & 200 & 21.0 & 94.6 & 32.1 & 24.1 & 43.8 \\
& 250 & 27.2 & 76.9 & 16.7 & 30.9 & 52.4 \\
& 300 & 39.1 & 74.8 & 13.9 & 27.1 & 59.0 \\
& 350 & 42.2 & 64.0 & 12.6 & 29.5 & 57.9 \\
\hline
\end{tabular}

1

The overall SRM reactivity trend for different metals based on methanol conversion followed the order of $\mathrm{Cu}>\mathrm{Pd}>\mathrm{Sn}>\mathrm{Ni} \approx \mathrm{Zn}>\mathrm{Co}$ with $\mathrm{Cu}-\mathrm{MCM}-41$ displaying the highest $\sim 82 \%$ methanol conversion at $350{ }^{\circ} \mathrm{C}$. However, if the catalyst performance is normalized based on the actual metal loading, $\mathrm{Pd}$ completely outperformed $\mathrm{Cu}$ among the two best catalysts. The relative SRM catalytic superiority of $\mathrm{Pd}$ and $\mathrm{Cu}$ catalysts are consistent with the results of Eswaramoorthi and Dalai [66] as well as Valdes-Solis et al. [67]. Eswaramoorthi and Dalai reported that at 300 ${ }^{\circ} \mathrm{C}$, SBA-15 supported $4.5 \mathrm{wt} \%$ Pd catalyst yielded as high as $86 \%$ methanol conversion. ValdesSolis et al. concluded that at $250{ }^{\circ} \mathrm{C}, \mathrm{Cu}$ catalysts showed initial high kinetic SRM activity. Compared to $\mathrm{Cu}$ and $\mathrm{Ni}$, other metal $(\mathrm{Zn}, \mathrm{Sn}, \mathrm{Ni}$ and $\mathrm{Co}$ ) showed almost half the methanol converions. The lower activity showed by Co-MCM-41 (14\% and $38 \%$ at 300 and $350{ }^{\circ} \mathrm{C}$, respectively) and Ni-MCM-41 (22\% and $45 \%$ at 300 and $350{ }^{\circ} \mathrm{C}$, respectively) could be attributed to their significantly lower reducibility owing to the silicates and silicides formation as discussed in the TPR studies (Fig. 7, and section above). The observed overall activity are consistent with most of the reported studies which have indicated that $\mathrm{Cu}$ and Pd based catalysts are most active 
1 for steam reforming $[66,67]$. However, it should be noted that when mesoporous $\mathrm{TiO}_{2}$ was used a

2 support in our earlier study, $\mathrm{Zn}$ and $\mathrm{Ni}$ showed showed significantly higher activity compared to

$3 \mathrm{Cu}$. This was attributed to the metal-support interactions leading to the lower reducibility of $\mathrm{Zn}$

4 and $\mathrm{Ni}$ in $\mathrm{TiO}_{2}$ matrix [53]. On the other hand, as observed in TPR analysis with MCM-41, the

5 metal particles seem to behave like bulk materials with advantage of higher surface area.

6 The selectivities of the product gases were quite different for each catalytic system. All the

7 catalysts displayed over $96 \%$ selectivity towards $\mathrm{H}_{2}$ except $\mathrm{Sn}-\mathrm{MCM}-41$ that showed a moderate

$878 \%$ average $\mathrm{H}_{2}$ selectivity. While $\mathrm{Cu}-\mathrm{MCM}-41$ and $\mathrm{Ni}-\mathrm{MCM}-41$ showed very little selevtivity $(0-$

$90.5 \%$ ) towards methane (undesirable product in this study), $\mathrm{Sn}-\mathrm{MCM}-41$ exhibited the highest $\mathrm{CH}_{4}$

10 methane selectivity $(\sim 58 \%)$. This explains the observed lower $\mathrm{H}_{2}$ selectivity for $\mathrm{Sn}$ at each reaction

11 temperature; the formation of a mole of $\mathrm{CH}_{4}$ consumes 3 moles of $\mathrm{H}_{2}$ (Eq. 5). In our recent study

12 with different $\mathrm{Cu}$ loadings in $\mathrm{Cu}-\mathrm{MCM}-41$, we showed that there is always some activity for

13 methanation reaction; however, at sufficient $\mathrm{Cu}$ loading, reforming of formed $\mathrm{CH}_{4}$ during $\mathrm{SRM}$

$14\left(\mathrm{CH}_{4}+\mathrm{H}_{2} \mathrm{O} \rightarrow \mathrm{CO}+3 \mathrm{H}_{2}\right)$ is a dominating reaction, thus producing only $0-1 \%$ of $\mathrm{CH}_{4}$ [21]. This

15 could also be the reason for the lower $\mathrm{CH}_{4}$ selectivity of $\mathrm{Ni}-\mathrm{MCM}-41$ although it is a good

16 methanation catalyst. For $\mathrm{Pd}$ and $\mathrm{Co}$, it could either be the same reason as for $\mathrm{Cu}$ or the lower

17 methanation activity observed for lower $\mathrm{CH}_{4}$ selectivity.

18 The selectivity towards $\mathrm{CO}$ production showed profound variations for different M-MCM-

1941 catalysts. The observed trend was $\mathrm{Cu}<\mathrm{Sn}<\mathrm{Co}<\mathrm{Zn}<\mathrm{Pd}<\mathrm{Ni}$. While the observed lower $\mathrm{CO}$

20 selectivity for $\mathrm{Cu}$ can be attributed to the better water gas shift reaction (WGSR) activity, for Sn it

21 is due to the higher methanatin activity. It is interesting to note that, on one hand, $\mathrm{Cu}$ which showed

22 least $\mathrm{CO}$ selectivity (e.g. $5.6 \%$ at $250{ }^{\circ} \mathrm{C}$ ) when supported in $\mathrm{MCM}-41, \mathrm{TiO}_{2}$ supported $\mathrm{Cu}$ showed

23 significantly higher $\mathrm{CO}$ selectivity (e.g. $57 \%$ at $250{ }^{\circ} \mathrm{C}$ ). On the other hand, $\mathrm{Zn}-\mathrm{TiO}_{2}$ showed 
1 considerably lower CO selectivity, 3\%, compared to $34 \%$ by Zn-MCM-41 [53]. The Pd and Ni

2 showed least CO selectivities among the different studied metals when supported both in MCM-

341 and $\mathrm{TiO}_{2}$, ascribed to the lower WGSR activity [53]. These results clearly indicate the role of

4 specific metal-support interactions in different metal-support systems.

5

6

7

8

\subsection{Stability Test of M-MCM-41 Catalysts for SRM}

The stability of the M-MCM-41 catalysts was examined to substantiate their ability to resist deactivation. This was carried out by running freshly reduced samples on stream continuously for $40 \mathrm{~h}$. The experiments were performed at $300^{\circ} \mathrm{C}$ under identical experimental conditions described previously in section 2.4. The methanol conversion for each M-MCM-41 catalyst over a period of $40 \mathrm{~h}$ on stream is presented in Fig. 8.

1

12

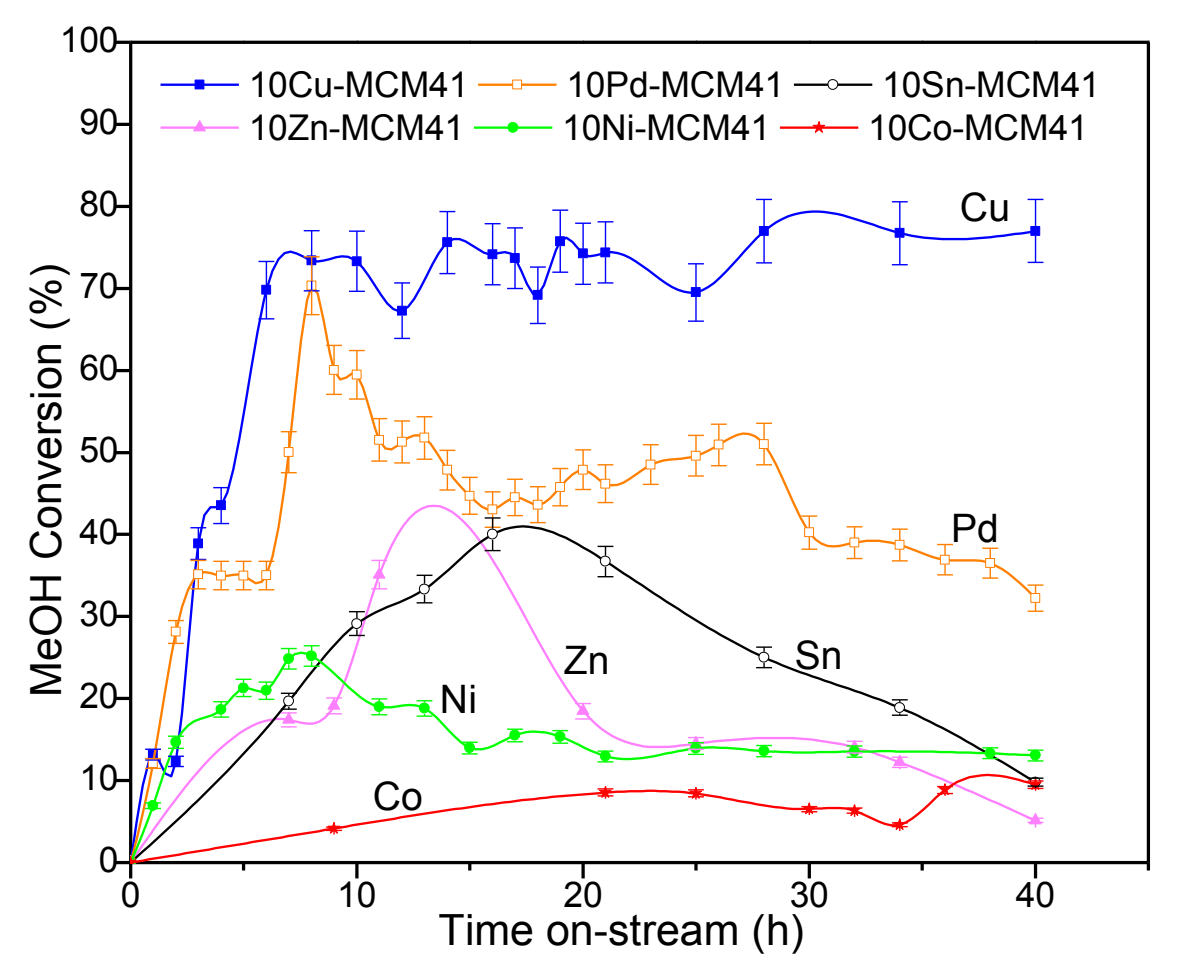

Fig. 8: Catalysts activity as a function of time on-stream during SRM. Reaction conditions: 300 ${ }^{\circ} \mathrm{C}, 1 \mathrm{~atm}$, methanol/water molar ratio of $1 / 3$ and a GHSV of $2838 \mathrm{~h}^{-1}$ at STP 
The initial increase in conversion with time is due to the unsteady state which was different for different catalysts. The trend of activity for $40 \mathrm{~h}$ on stream was similar to SRM catalytic performance discussed in section $4(\mathrm{Cu}>\mathrm{Pd}>\mathrm{Sn}>\mathrm{Ni} \approx \mathrm{Zn}>\mathrm{Co})$. Cu-MCM-41 was observed to be the most stable, maintaining $\sim 74 \%$ conversion and no apparent signs of deactivation for 10 to 40 h. Except for Cu-MCM-41 and Co-MCM-41, all other catalysts showed decline in conversion after attaining the short steady state with respective highest conversions. Although, Co-MCM-41 showed no decline in conversion, it was always less than $10 \%$ until the end of $40 \mathrm{~h}$. For Ni-MCM41, after initial decline, the conversion was steadied at $14 \%$. However, for $\mathrm{Pd}, \mathrm{Zn}$ and $\mathrm{Sn}$, the conversion kept decreasing with time-on-steam, indicating continuous deactivation over the time. For example, methanol conversion for Pd-MCM-41 decreased rapidly to $\sim 30 \%$, representing less than 50\% SRM activity compared to that of Cu-MCM-41 at the end of $40 \mathrm{~h}$. Sn and $\mathrm{Zn}$ also showed a decline in methanol conversion to $\sim 20 \%$ and $\sim 30 \%$, respectively, for the period of 10 $40 \mathrm{~h}$ on stream. The effect of time-on-stream on the selectivities of the product gas mixture is presented in Fig. S1 (supplemental information). Duration on stream did not seem to have any dramatic effect on the selectivities of $\mathrm{H}_{2}, \mathrm{CO}, \mathrm{CH}_{4}$ and $\mathrm{CO}_{2}$ except that the $\mathrm{CH}_{4}$ selectivity for $\mathrm{Sn}$ MCM-41 started to decrease significantly after $20 \mathrm{~h}$ reaching about $18 \%$ at the end of $40 \mathrm{~h}$.

\subsection{Characterization of Spent M-MCM-41 Catalysts}

Characterization of spent catalysts after SRM reactions was carried out to investigate the effect of reaction time on the physicochemical properties and the possible causes of deactivation of the catalysts. The SAXRD and WAXRD patterns of spent catalysts are shown in Fig. 9 (a) and (b), respectively. 

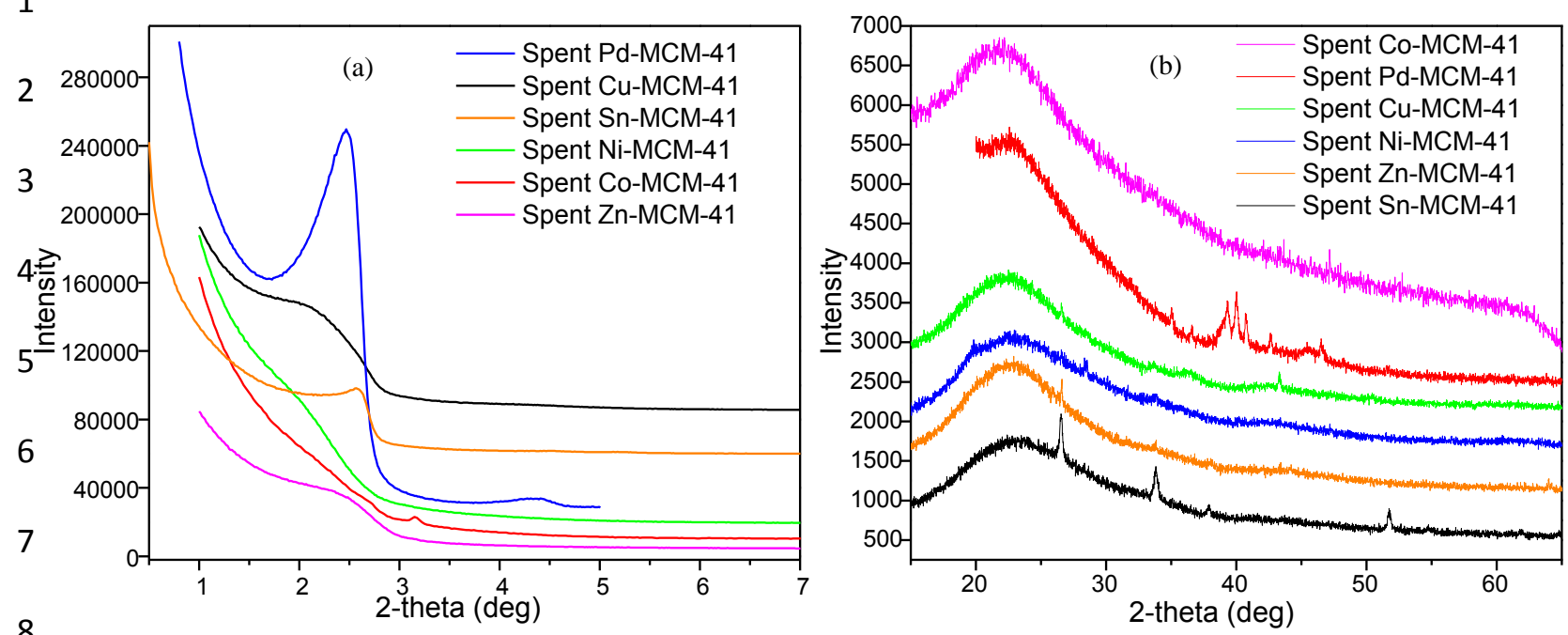

Fig. 9: (a) Small angle and (b) wide angle XRD diffraction profiles of spent catalysts

Fig. 9(a) showed that SAXRD peak intensity for all the spent catalysts except that of spent PdMCM-41 decreased drastically comparted to fresh catalysts indicating deterioration of the ordered structure after the $40 \mathrm{~h}$ time-on-stream experiments. The BET surface areas of the spent catalysts shown in Table 1 are consistent with SAXRD results. After $40 \mathrm{~h}$ on-stream, all the catalysts retained an appreciable surface area. Pd-MCM-41 showed $\sim 32 \%$ decrease in surface area while $\mathrm{Co}$ and $\mathrm{Cu}$ recorded the highest decline of $\sim 44 \%$. Concomitantly about $15-30 \%$ loss of total pore volume was observed for all spent catalysts. With the exception of Zn-MCM-41, that lost $\sim 25 \%$ of its pore size, all other catalysts essentially maintained their pore morphology; hence some degree of ordered mesoporosity. Thus, the results indicate that the M-MCM-41 catalysts have issues in terms of hydrothermal stability under the reaction conditions.

The WAXRD patterns of the spent catalysts shown in Fig. 9(b) were essentially similar to

21 the fresh catalysts with slight modifications. The noticeable differences were observed in WAXRD

22 profiles of fresh (Fig. 3(b)) and spent (Fig. 9(b)) Pd-MCM-41, Cu-MCM-41 and Sn-MCM-41

23 catalysts. The diffraction peak of $\mathrm{PdO}$ centered at $2 \theta$ value of $33.9^{\circ}$ indexed to (101) as well as the 
$35.6^{\circ}$ and $38.9^{\circ}$ peaks of $\mathrm{CuO}$ crystallites in the fresh catalysts disappeared after $40 \mathrm{~h}$ of reaction.

2 The emergence of new moderate intensity diffraction peaks $\left(2 \theta=38.5^{\circ}, 39.3^{\circ}, 40^{\circ}\right)$ for Pd-MCM-

341 indicated structural transformation after 40h of SRM. While the diffraction peak at $2 \theta$ around

$440^{\circ}$ is indexed to (111) reflections of the PdO-crystallites [68, 69]; those at $38.5^{\circ}$, and $39.3^{\circ}$ are

5 attributed to the formation of palladium carbide (Pd-C) [70-72]. The researchers showed that in

6 the presence of carbon containing gases, Pd reacts (even $<200{ }^{\circ} \mathrm{C}$ ) with carbon to form a

7 metastable Pd-C phase. The moderately intense oxide diffraction peak of Sn and the very weak

8 ones of $\mathrm{Zn}, \mathrm{Ni}, \mathrm{Cu}$ at $2 \theta=26.8-29.4^{\circ}$ indicated crystallographic traces of carbon (002) reflections

9 [73-75]. For Sn-MCM-41, a significant increase in crystallinity of the Sn oxides was observed.

10 The appearance of strong peaks at $2 \theta=26.8^{\circ}, 34.2^{\circ}, 38.5^{\circ}, 52.2^{\circ}$ are indexed to the $\mathrm{SnO}_{2}(110)$,

11 (101), (200), (211) crystallographic planes, respectively [76]. The $\mathrm{SnO}_{2}$ crystal size calculated

12 using Eq. (1) was $33.8 \mathrm{~nm}$. The appearance of the $\mathrm{SnO}_{2}$ peaks in the spent $\mathrm{Sn}-\mathrm{MCM}-41$ catalysts

13 suggests possible thermal sintering of the $\mathrm{SnO} / \mathrm{SnO}_{2}$ oxides.

In order to estimate the extent of coke deposition the spent catalysts were subjected to

TGA-DSC under air environment. TGA-DSC themograms displayed in Fig. S2 indicated that

16 spent catalysts recorded a nominal $0.25 \%-0.96 \%$ coke formation between $400{ }^{\circ} \mathrm{C}$ and $570{ }^{\circ} \mathrm{C}$ that

17 has usually been attributed to amorphous and graphitic carbon [16, 77]. It should be noted that Zn-

18 MCM-41 and Cu-MCM-41 showed the lowest temperature of coke oxidation among different

19 catalysts indicating amorphous nature of the deposited coke. The absence of cleavable $\mathrm{C}-\mathrm{C}$ bonds

20 in methanol suggests the carbon deposit most likely occurred by the disproportionation of carbon

21 monoxide (Boudouard reaction) $2 \mathrm{CO} \rightarrow \mathrm{CO}_{2}+\mathrm{C}[78,79]$. In order to determine the role of coke

22 in the catalyst deactivatin, we activated the spent Pd-MCM-41 (40 h time-on-stream) as a

23 representative catalyst in-situ using air. The reuse of the activated catalyst for SRM showed 
1 complete recovery of catalyst activity. This indicates that coking plays a major role in the

2 deactivation of the catalysts. The absence of coke effect on Cu-MCM-41 activity could be

3 attributed to the amorphous nature of the coke. However, given the amorphous nature of coke, the

4 decreased activity of Zn-MCM-41 suggests that although coke deposition seems to be major cause

5 of deactivation, other mechanisms such as structural degradation and sintering may also be

6 contributing to the catalysts deactivation.

\section{5. Conclusions}

Comparative performances of $\mathrm{Cu}, \mathrm{Co}, \mathrm{Ni}, \mathrm{Pd}, \mathrm{Zn}$, and $\mathrm{Sn}$ catalysts incorporated in high 9 surface area MCM-41 matrix were investigated for methanol steam reforming. These catalysts were synthesized using an optimized one pot hydrothermal procedure. The small angle XRD and

$11 \mathrm{~N}_{2}$ adsorption-desorption studies corroborated the ordered structure of the MCM-41 matrix and 12 the retention of the ordered structure after incorporation of $10 \mathrm{wt} \%$ of the metals. Of all the 13 catalysts studied, Cu-MCM-41 and Pd-MCM-41 exhibited dominant SRM activity. Cu-MCM-41 14 showed the best catalytic performance with $68 \%$ methanol conversion and $100 \% \mathrm{H}_{2}, 6 \% \mathrm{CO}$ 15 selectivity with no noticeable $\mathrm{CH}_{4}$ formation at $\sim$ at $250{ }^{\circ} \mathrm{C}$ While $\mathrm{Cu}-\mathrm{MCM}-41$ strongly enhanced 16 the WGSR, Pd-MCM-41 and Ni-MCM-41 catalysts showed least activity for WGSR resulting in 17 higher $\mathrm{CO}$ selectivities. With regards to catalysts stability, $\mathrm{Cu} / \mathrm{MCM} 41$ was the most stable and 18 displayed consistent steady state conversion (up to74\%) over $40 \mathrm{~h}$ time-on-stream. Although 19 coking played an influential role in deactivation of most catalysts, thermal sintering and changes 20 in MCM-41 structure also could be responsible for the catalyst deactivation. Comparision of M-

21 MCM-41 characteristics and SRM performance over $\mathrm{M}-\mathrm{TiO}_{2}$ in our earlier studies suggest that

22 metal particles in MCM-41 behave like bulk materials having no significant metal-support 23 interaction as observed in $\mathrm{M}-\mathrm{TiO}_{2}$ catalysts. 
2 The authors express their profound gratitude to the National Science Foundation (NSF) for funding

3 the NSF-CREST Bioenergy Center (Grant No. HRD-124215). Our sincere gratitude goes to Dr.

4 Keith Schimmel (EES Dept. Chairperson) for his financial assistance. We would like to thank $\mathrm{Mr}$

5 James King (Chemistry Department) for supporting our experimental work and Mr. Bryce Holmes

6 (School of Agriculture and Environmental Sciences) for his assistance with ICP-OES analysis.

7 The authors thank Dr. Sankar and Dr. Yarmolenko (Center for Advanced Materials and Smart

8 Structures-CAMSS) at NCAT for the use of their XRD for material characterization. Finally, we

9 thank Dr. Abolghasem Shahbazi (Biological and Chemical Engineering Dept. Chairperson) and

10 Dr. Lijun Wang for the use of his Chemical Analyzer for TPR and TGA studies and Dr.

11 Shamsuuddin Illias (Chemical Engineering Department) for his assistance with BET analysis.

\section{References}

13 [1] S. Sá, H. Silva, L. Brandão, J.M. Sousa, A. Mendes, Appl. Catal. B Environ. 99 (2010) 431457.

15 [2] D.R. Palo, R.A. Dagle, J.D. Holladay, Chem. Rev. 107 (2007) 3992-4021.

16 [3] B. Lorenzut, T. Montini, L. De Rogatis, P. Canton, A. Benedetti, P. Fornasiero, Appl. 17 Catal. B Environ. 101 (2011) 397-408.

18 [4] L. Zhang, L. Pan, C. Ni, T. Sun, S. Zhao, S. Wang, A. Wang, Y. Hu, Int. J. Hydrogen 19 Energy. 38 (2013) 4397-4406.

20 [5] P. Hirunsit, K. Faungnawakij, J. Phys. Chem. C. 117 (2013) 23757-23765.

21 [6] A. Jomekian, S.A.A. Mansoori, B. Bazooyar, A. Moradian, J. Porous Mater. 19 (2012) $22979-988$.

23 [7] G. Wang, Z. Liu, Y. Liu, G. Liu, M. Xu, L. Wang, Chin. J. Catal. 29 (2008) 1159-1164.

24 [8] V. Nichele, M. Signoretto, F. Menegazzo, A. Gallo, V. Dal Santo, G. Cruciani, G. Cerrato, 25 Appl. Catal. B Environ. 111 (2012) 225-232.

26 [9] R.Y. Abrokwah, V.G. Deshmane, D. Kuila, Adv. Mater. Res. 1096 (2015) 161-168. 
[10] K. Kosaraju, A. Rahman, M. Duncan, B. Tatineni, Y. Basova, V. Deshmane, R. Abrokwah,

2 S. Hosseinnezhad, J. King, S. Ilias, Future Energy Environ. Mater. 88 (2014) 337-344.

3 [11] E. Yamamoto, K. Kuroda, Bull. Chem. Soc. Jpn. 89 (2016) 501-539.

4 [12] V. Malgras, Q. Ji, Y. Kamachi, T. Mori, F.-K. Shieh, K.C.-W. Wu, K. Ariga, Y. Yamauchi, 5 Bull. Chem. Soc. Jpn. 88 (2015) 1171-1200.

6 [13] N. Song, Y.-W. Yang, Chem. Soc. Rev. 44 (2015) 3474-3504.

7 [14] R. Riva, H. Miessner, R. Vitali, G. Del Piero, Appl. Catal. A Gen. 196 (2000) 111-123.

8 [15] A.N. Fatsikostas, D.I. Kondarides, X.E. Verykios, Catal. Today. 75 (2002) 145-155.

9 [16] D. Liu, R. Lau, A. Borgna, Y. Yang, Appl. Catal. A Gen. 358 (2009) 110-118.

10 [17] E. Ozdogan, T. Dogu, G. Dogu, Int. J. Chem. Reactor Eng. 5 (2007) 1-11.

11 [18] L. Bobadilla, S. Palma, S. Ivanova, M. Domínguez, F. Romero-Sarria, M. Centeno, J. 12 Odriozola, Int. J. Hydrogen Energy. 38 (2013) 6646-6656.

13 [19] J.S. Lee, G.B. Han, M. Kang, Energy. 44 (2012) 248-256.

14 [20] A. Ota, E.L. Kunkes, I. Kasatkin, E. Groppo, D. Ferri, B. Poceiro, R.M.N. Yerga, M. 15 Behrens, J. Catal. 293 (2012) 27-38.

16 [21] V.G. Deshmane, R.Y. Abrokwah, D. Kuila, Int. J. Hydrogen Energy. 40 (2015) 104391710452.

18 [22] M. Jaroniec, L.A. Solovyov, Langmuir. 22 (2006) 6757-6760.

19 [23] M. Ugalde, E. Chavira, M. Ochoa-Lara, I. Figueroa, C. Quintanar, A. Tejeda, J. Nanotech. 202013 (2013).

21 [24] L. Huang, Y. Wang, Z. Wang, F. Chen, J. Tan, P.K. Wong, Phys. Chem. 2 (2012) 27-34.

22 [25] P.S.S. Reddya, N.S. Babua, N. Lingaiaha, P.S. Prasada, I. Raob, Europian Congress of 23 Chemical Engineering, Copenhagen, Denmark, 2007, pp. 1-12.

24 [26] R. Singh, S. Kulkarni, N. Naik, Adv. Mater. Lett. 4 (2013) 82-88.

25 [27] C. Li, S. Liu, J. Nanomater. 2012 (2012) 1-6.

26 [28] N.C. Pramanik, S. Das, P.K. Biswas, Mater. Lett. 56 (2002) 671-679.

27 [29] S. Biz, M.L. Occelli, Catal. Rev. 40 (1998) 329-407.

28 [30] D. Liu, X.Y. Quek, W.N.E. Cheo, R. Lau, A. Borgna, Y. Yang, J. Catal. 266 (2009) 38029390.

30 [31] S.Z. Islam, V.G. Deshmane, S. Ilias, Sep. Sci. Technol. (2015).

31 [32] M. Zienkiewicz-Strzałka, S. Pikus, Appl. Surf. Sci. 261 (2012) 616-622. 
1 [33] J. Panpranot, K. Pattamakomsan, J.G. Goodwin Jr, P. Praserthdam, Catal. Commun. 5 2 (2004) 583-590.

3 [34] S. Chaliha, K.G. Bhattacharyya, J. Hazard. Mater. 150 (2008) 728-736.

4 [35] F. Adam, T.-S. Chew, The Open Colloid Sci. J. 5 (2012) 1-4.

5 [36] V.G. Deshmane, Y.G. Adewuyi, Microporous Mesoporous Mater. 148 (2012) 88-100.

6 [37] N.I. Taib, S. Endud, M.N. Katun, Int. J. Chem. 3 (2011) 2.

7 [38] C. Huo, J. Ouyang, H. Yang, Sci. Rep. 4 (2014) 1-9.

8 [39] Z. Zhang, J. Suo, X. Zhang, S. Li, Appl. Catal. A Gen. 179 (1999) 11-19.

9 [40] E.L. Lee, I.E. Wachs, J. Phys. Chem. C. 112 (2008) 6487-6498.

10 [41] Y. Borodko, J.W. Ager, G.E. Marti, H. Song, K. Niesz, G.A. Somorjai, J. Phys. Chem. B. 11109 (2005) 17386-17390.

12 [42] Z. Zhang, Y. Han, F.-S. Xiao, S. Qiu, L. Zhu, R. Wang, Y. Yu, Z. Zhang, B. Zou, Y. Wang, 13 J. Am. Chem. Soc. 123 (2001) 5014-5021.

14 [43] I.E. Wachs, Catal. Today. 27 (1996) 437-455.

15 [44] N.W. Hurst, S.J. Gentry, A. Jones, B.D. McNicol, Catal. Rev. Sci. Eng. 24 (1982) 23316309.

17 [45] Y. Matsumura, H. Ishibe, Appl. Catal. B Environ. 86 (2009) 114-120.

18 [46] A. Vizcaíno, A. Carrero, J. Calles, Int. J. Hydrogen Energy. 32 (2007) 1450-1461.

19 [47] L. Kundakovic, M. Flytzani-Stephanopoulos, Appl. Catal. A Gen. 171 (1998) 13-29.

20 [48] P. Barnes, M. Tiernan, G. Parkes, J. Therm. Anal. Calorim. 56 (1999) 733-737.

21 [49] M. Rafati, L. Wang, A. Shahbazi, J. CO2 Utilization. 12 (2015) 34-42.

22 [50] B.D. Adams, A. Chen, Mater. Today. 14 (2011) 282-289.

23 [51] C.-W. Chou, S.-J. Chu, H.-J. Chiang, C.-Y. Huang, C.-j. Lee, S.-R. Sheen, T.P. Perng, C.24 t. Yeh, J. Phys. Chem. B. 105 (2001) 9113-9117.

25 [52] B. Pawelec, S. Damyanova, K. Arishtirova, J.L.G. Fierro, L. Petrov, Appl. Catal. A Gen. 26323 (2007) 188-201.

27 [53] V.G. Deshmane, S.L. Owen, R.Y. Abrokwah, D. Kuila, J. Mol. Catal. A: Chem. 408 (2015) $28 \quad 202-213$.

29 [54] J. Van de Loosdrecht, A. Van der Kraan, A. Van Dillen, J. Geus, J. Catal. 170 (1997) 21730226. 
1 [55] W.-J. Shen, M. Okumura, Y. Matsumura, M. Haruta, Appl. Catal. A Gen. 213 (2001) 2252232.

3 [56] J.P. Bucher, J. Van der Klink, M. Graetzel, J. Phys. Chem. 94 (1990) 1209-1211.

4 [57] C. Hippe, R. Lamber, G. Schulz-Ekloff, U. Schubert, Catal. Lett. 43 (1997) 195-199.

5 [58] E. van Steen, G.S. Sewell, R.A. Makhothe, C. Micklethwaite, H. Manstein, M. de Lange, 6 C.T. O'Connor, J. Catal. 162 (1996) 220-229.

7 [59] T. Ueckert, R. Lamber, N. Jaeger, U. Schubert, Appl. Catal. A Gen. 155 (1997) 75-85.

8 [60] R. Lamber, N. Jaeger, G. Schulz-Ekloff, J. Catal. 123 (1990) 285-297.

9 [61] F. Boubekr, A. Davidson, S. Casale, P. Massiani, Microporous Mesoporous Mater. 141 10 (2011) 157-166.

11 [62] N. Osakoo, R. Henkel, S. Loiha, F. Roessner, J. Wittayakun, Appl. Catal. A Gen. 464 12 (2013) 269-280.

13 [63] R. Kam, C. Selomulya, R. Amal, J. Scott, J. Catal. 273 (2010) 73-81.

14 [64] S. Lew, A. Sarofim, M. Flytzani-Stephanopoulos, Chem. Eng. Sci. 47 (1992) 1421-1431.

15 [65] S.-W. Park, O.-S. Joo, K.-D. Jung, H. Kim, S.-H. Han, Appl. Catal. A Gen. 211 (2001) 811690.

17 [66] I. Eswaramoorthi, A. Dalai, Int. J. Hydrogen Energy. 34 (2009) 2580-2590.

18 [67] T. Valdes-Solis, G. Marban, A. Fuertes, Catal. Today. 116 (2006) 354-360.

19 [68] C.-M. Lin, T.-L. Hung, Y.-H. Huang, K.-T. Wu, M.-T. Tang, C.-H. Lee, C. Chen, Y. Chen, 20 Physical Review B. 75 (2007) 125426.

21 [69] S. Moisan, V. Martinez, P. Weisbecker, F. Cansell, S. Mecking, C. Aymonier, J. Am. 22 Chem. Soc. 129 (2007) 10602-10606.

23 [70] S. Ordóñez, F.V. Díez, H. Sastre, Appl. Catal. B Environ. 31 (2001) 113-122.

24 [71] E. Van de Sandt, A. Wiersma, M. Makkee, H. Van Bekkum, J. Moulijn, Appl. Catal. A 25 Gen. 155 (1997) 59-73.

26 [72] S. Ziemecki, G. Jones, D. Swartzfager, R. Harlow, J. Faber Jr, J. Am. Chem. Soc. 107 27 (1985) 4547-4548.

28 [73] F.D. Nayeri, S. Darbari, E.A. Soleimani, S. Mohajerzadeh, J. Phys. D: Appl. Phys. 45 29 (2012) 285101-285111.

30 [74] C.K. Cheng, S.Y. Foo, A.A. Adesina, Catal. Today. 164 (2011) 268-274. 
1 [75] K.M. Hardiman, T.T. Ying, A.A. Adesina, E.M. Kennedy, B.Z. Dlugogorski, Chem. Eng. 2 J. 102 (2004) 119-130.

3 [76] G. De, R. Köhn, G. Xomeritakis, C.J. Brinker, Chem. Commun. (2007) 1840-1842.

4 [77] S. Arepalli, P. Nikolaev, O. Gorelik, V.G. Hadjiev, W. Holmes, B. Files, L. Yowell, 5 Carbon. 42 (2004) 1783-1791.

6 [78] N. Laosiripojana, S. Assabumrungrat, J. Power Sources. 163 (2007) 943-951.

7 [79] M.V. Twigg, M.S. Spencer, Top. Catal. 22 (2003) 191-203.

8

9 GRAPHICAL ABSTRACT

10

11

12
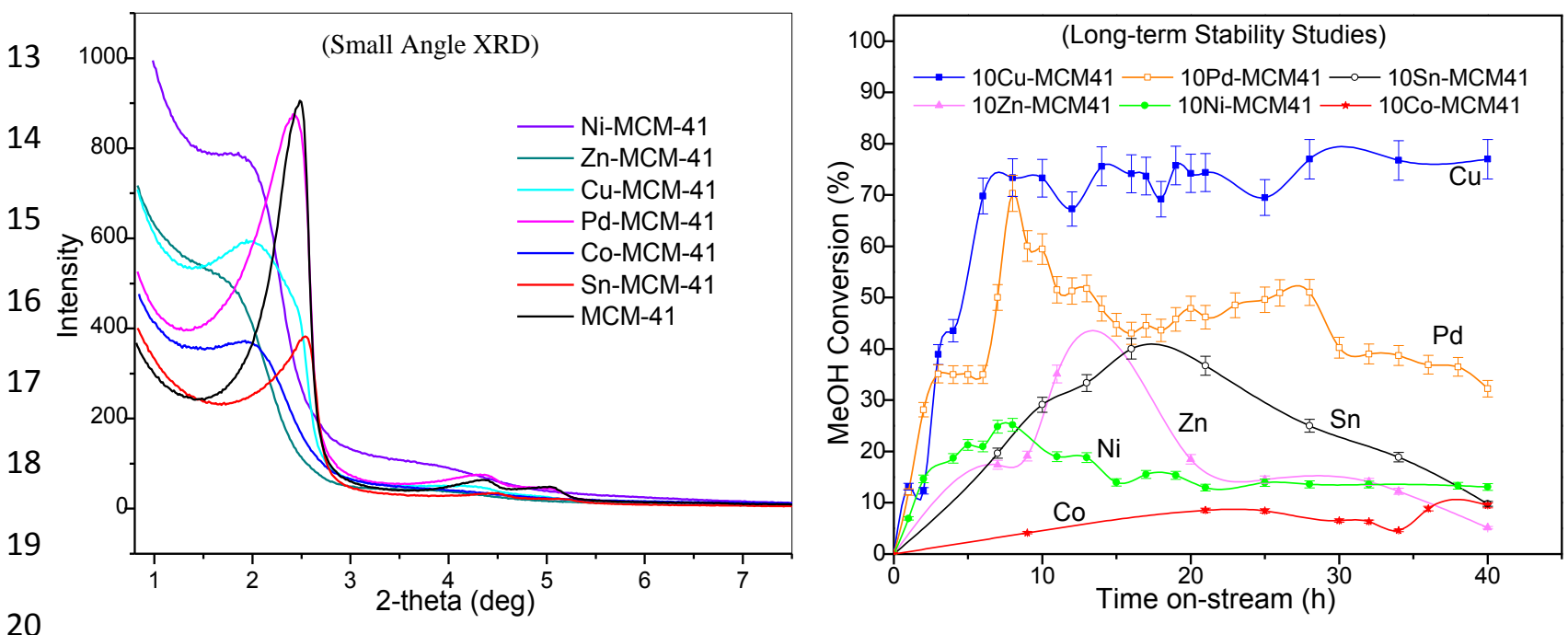

21

22

23

24 